Gerión. Revista de Historia Antigua

ISSN: 0213-0181

https://dx.doi.org/10.5209/geri.78125

\title{
Más allá de los castella tutiora: la ocupación de asentamientos fortificados en el noroeste peninsular (siglos IV-VI) ${ }^{1}$
}

\author{
Carlos Tejerizo García²; Celtia Rodríguez González ${ }^{3}$
}

Recibido: 16 de febrero de 2021 / Aceptado: 12 de marzo de 2021

Resumen. Las ocupaciones romanas tardías de los castros en el noroeste peninsular son un fenómeno que, si bien fue reconocido hace ya varias décadas, ha sido pocas veces abordado de forma sistemática. Esto es debido a una historiografía que ha primado, o bien las interpretaciones de larga duración histórica sobre estos sitios, o bien las lecturas a través del paradigma de los castella tutiora de la tradición hidaciana. En este trabajo se propone una primera revisión exhaustiva de estos contextos para resaltar los límites y posibilidades de las interpretaciones tradicionales. Así, se propondrá un enfoque contextual y estratigráfico para definir en términos complejos este fenómeno, sugiriendo como hipótesis una interpretación en clave social que pone en el centro explicativo los diversos procesos históricos que sucedieron al final del Imperio Romano de Occidente.

Palabras clave: castros; fin del Imperio Romano; Alta Edad Media; sistema de poblamiento; revisión crítica.

\section{[en] Beyond the Castella Tutiora: Fortified Settlements in Northwestern Iberia $\left(4^{\text {th }}-6^{\text {th }}\right.$ Centuries $)$}

\begin{abstract}
The Late Roman occupation of northwestern Iberian hill-forts is a phenomenon which, even if recognised at length, has rarely been tackled in detail. This is due to a historiography that traditionally prioritised those interpretations from the perspective of the long duration or those regarding the paradigm of the castella tutiora from Hydatius' writings. In this paper we propose an exhaustive revision of these contexts to pinpoint the setbacks and possibilities of those traditional interpretations. Thus, we will suggest a contextual and stratigraphical approach in order to define the complexity of the phenomenon, proposing as a hypothesis a social interpretation which focus on the diversity of historical processes that occurred by the end of the Western Roman Empire.
\end{abstract}

Keywords: Hillforts; End of the Roman Empire; Early Middle Ages; Settlement Pattern; Critical Review.

Sumario. 1. Introducción. 2. La ocupación tardía de los castros como problema conceptual e historiográfico. 3. Los asentamientos fortificados en el noroeste peninsular. Construyendo la casa por los cimientos. 4. Algunas consideraciones interpretativas sobre los asentamientos fortificados de los siglos IV-VI en el noroeste peninsular. 5. Balance y perspectiva de trabajo. 6. Referencias bibliográficas.

Cómo citar: Tejerizo García, C.; Rodríguez González, C. (2021): Más allá de los castella tutiora: la ocupación de asentamientos fortificados en el noroeste peninsular (siglos IV-VI), en Gerión 39(2), 717-745.

1 Este trabajo se ha realizado en el marco del proyecto MSCA IF "INPACT-Industrialization and the process of modernity: the archaeological transformation of the rural world (18th-21st c.)" (GA n.101032402), así como del proyecto "Arqueología de las sociedades locales en el sur de Europa: identidades, colectivos y territorialidades (siglos V-XI)" (PID2020-112506GB-C41).

2 Università degli Studi di Genova

E-mail: carlos.tejerizo.garcia@edu.unige.it

ORCID: 0000-0001-9479-2720

3 Universidad de Santiago de Compostela.

E-mail: celtia.rodriguez@rai.usc.es

ORCID: 0000-0002-1996-0947 


\section{Introducción ${ }^{4}$}

Es indudable la centralidad del "castro" en la historiografía del norte y noroeste peninsular. Según el Diccionario de la Real Academia Española, el castro se define como "poblado fortificado en la Iberia romana". Sin embargo, en el caso del norte cantábrico y Galicia, esta definición se desborda, encerrando profundos significados históricos, culturales e, incluso, ideológicos. ${ }^{5}$ Significados que van más allá de la conceptualización de un tipo particular de asentamiento y que se visibiliza, por ejemplo, en el hecho de que ha sido el eje vertebrador de toda una cultura, la cultura castreña o "castrexa". ${ }^{6}$ Una cultura vinculada comúnmente (pero no sólo) al mundo celta y cuyos límites cronológicos, geográficos y étnicos han sido muy difusos tanto en el pasado como en el presente, lo que ha generado diversas discusiones interpretativas. ${ }^{7}$ Más aún, la caracterización de la cultura castreña, definida fundamentalmente a través de este tipo de asentamientos, se ha realizado en ocasiones a partir de una base empírica muy débil que ha generado ciertas distorsiones analíticas de gran calado interpretativo, como ha ocurrido en otros ámbitos geográficos. ${ }^{8}$

Una de estas distorsiones en el análisis de los castros ha sido la de asumir de forma apriorística cuestiones tan relevantes como la secuencia de ocupación o la cronología en algunos de los asentamientos, produciendo en ocasiones larguísimas ocupaciones de siglos, si no de milenios, sin que la evidencia empírica disponible lo sustente o sin considerar las posibles soluciones de continuidad o cambios en la estructuración de los asentamientos. ${ }^{9}$ Así, la posible existencia de fases de ocupación específicas vinculadas a momentos históricos concretos queda diluida dentro de una narrativa de continuidad y larga duración que desdibuja en gran medida las causas políticas, sociales y económicas detrás de la ocupación efectiva del sitio en contextos determinados. Uno de los períodos de ocupación de este tipo de asentamientos que ha quedado especialmente diluido historiográficamente ha sido el de la época romana tardía y los primeros siglos altomedievales (siglos IV-VI), que, si bien ha sido reconocido y caracterizado en diversos trabajos, ${ }^{10}$ sólo en contadas ocasiones ha sido objeto de estudios particulares,$^{11}$ normalmente vinculados a narrativas de larga duración que se centraban sólo parcialmente este período. ${ }^{12}$ De esta manera, la categoría de "castro" queda desvirtuada por las cargas y distorsiones que el propio concepto conlleva, disminuyendo su capacidad analítica, ${ }^{13}$ lo que ha perjudicado especialmente la interpretación de estas ocupaciones en el contexto del final del Imperio romano. ${ }^{14}$ En palabras de A. Rodríguez Resino: "hasta ahora los castros más tardíos, de tiempos plenamente históricos, han pasado desapercibidos salvo contadas excepciones". ${ }^{15}$

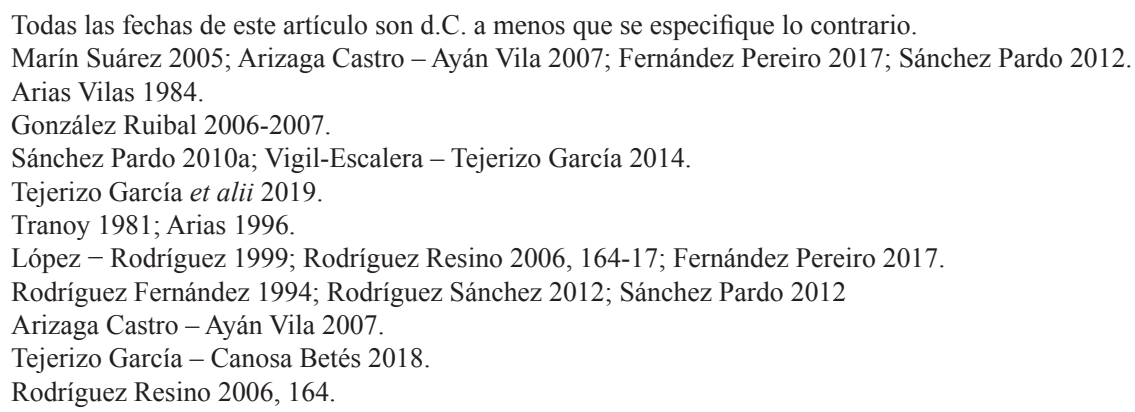

Todas las fechas de este artículo son d.C. a menos que se especifique lo contrario.

Marín Suárez 2005; Arizaga Castro - Ayán Vila 2007; Fernández Pereiro 2017; Sánchez Pardo 2012.

Arias Vilas 1984.

González Ruibal 2006-2007.

Sánchez Pardo 2010a; Vigil-Escalera - Tejerizo García 2014.

Tejerizo García et alii 2019.

Tranoy 1981; Arias 1996.

López - Rodríguez 1999; Rodríguez Resino 2006, 164-17; Fernández Pereiro 2017.

Rodríguez Fernández 1994; Rodríguez Sánchez 2012; Sánchez Pardo 2012

Arizaga Castro - Ayán Vila 2007.

Tejerizo García - Canosa Betés 2018.

Rodríguez Resino 2006, 164. 
Esta situación, sin embargo, está cambiando. En la última década se ha producido una auténtica renovación en los estudios arqueológicos del período entre el fin del Imperio romano y el inicio de la Alta Edad Media que están resituando, entre otras muchas cuestiones, el papel de los castros con ocupaciones tardías en el noroeste peninsular. ${ }^{16}$ En este proceso historiográfico confluyen una renovación conceptual, un aumento de las excavaciones arqueológicas (sobre todo de aquellas vinculadas a la denominada arqueología comercial) y diversos proyectos de investigación dirigidos específicamente hacia este período, que han permitido una "revolución silenciosa" en el noroeste peninsular paralela a la que ha ocurrido en toda la Península Ibérica. ${ }^{17}$ Sin embargo, mucha de la información arqueológica generada en este período está muy dispersa o es aún inédita, ${ }^{18}$ por lo que una gran parte de los estudios sobre el período todavía han de basarse no sólo en informaciones y excavaciones antiguas, sino también en viejos paradigmas que entran en contradicción con la evidencia empírica disponible. ${ }^{19}$ Esto ha ocasionado la necesidad tanto de revisar de forma crítica algunos contextos e interpretaciones como de elaborar nuevas hipótesis de trabajo sobre diversas cuestiones de la historiografía del noroeste peninsular, como el papel del comercio en el mundo tardo-romano y altomedieval, ${ }^{20}$ la expansión de las primeras iglesias cristianas en relación al poder aristocrático, ${ }^{21} \mathrm{o}$ la construcción del reino suevo. ${ }^{22}$

En este proceso de renovación historiográfica, las transformaciones en el sistema de poblamiento y el papel específico que jugaron los castros durante los siglos IV al VI están siendo objeto de una revisión particular a partir de los nuevos datos provenientes de diversas excavaciones y proyectos de investigación recientes ${ }^{23}$ Este trabajo tiene el objetivo principal de realizar una primera aproximación crítica al fenómeno de la ocupación de los asentamientos fortificados en el período entre los siglos IV y VI en el noroeste peninsular a partir, por un lado, de la recopilación de la información de las intervenciones arqueológicas antiguas y, por otro, de los nuevos datos disponibles. Así, se pretende particularizar estos sitios como un fenómeno histórico vinculado a un contexto político y social específico, desvinculados de una narrativa de larga duración, así como apoyada en la evidencia empírica efectivamente presente en el contexto arqueológico. Esto, esperamos, permitirá plantear hipótesis y preguntas para futuras investigaciones desde una perspectiva crítica, libre de apriorismos y determinismos historiográficos.

El trabajo se dividirá en cuatro partes. En primer lugar, se realizará un análisis historiográfico y conceptual crítico sobre los asentamientos fortificados, así como de las categorías de "castro" o "galaico-romano", resaltando los problemas analíticos e interpretativos que generan. En segundo lugar, se presentará la información arqueológica recopilada hasta el momento sobre este tipo de asentamientos, valorando sus posibilidades y sus límites. En tercer lugar, se realizarán algunos apuntes e hipótesis sobre su interpretación en el contexto histórico en el que se insertan, esto

\footnotetext{
Sánchez Pardo 2010a; 2010b.

Quirós Castillo 2018.

Sánchez Pardo 2013.

Rodríguez Resino 2006.

Fernández Fernández 2014.

Sánchez Pardo 2015.

Díaz Martínez 2011.

Tejerizo García et alii 2019.
} 
es, el fin del dominio imperial romano y las transformaciones que conducirán al mundo altomedieval. Finalmente, se resaltarán algunas perspectivas de trabajo para el futuro de la investigación sobre el tema.

\section{La ocupación tardía de los castros como problema conceptual e historiográfico}

En su clásico libro La Galice Romaine, Alain Tranoy afirmaba que

En même temps que l'on constate un développement de la propriété agricole organisée autour d'une villa, de nombreux indices montrent que les anciens castros connaissent au III et au IV siècle un regain d'activité. Là encore, les difficultés sont considérables, car de nombreux sites de castros sont mal connus ou incomplètement fouillés. ${ }^{24}$

Se trata de uno de los primeros estudios sobre el noroeste peninsular que particulariza una ocupación romana tardía específica, al mismo tiempo que reconoce las limitaciones para su estudio por la falta de evidencias empíricas. Hasta ese momento, si bien se habían excavado numerosos contextos que mostraban la presencia de estas fases a través de materiales o hallazgos puntuales (fundamentalmente, terra sigillata tardía o numerario de los siglos III y IV), o bien se habían incluido dentro de narrativas de larga duración sobre la cultura castreña, o bien se consideraron como epifenómenos "anecdóticos" en el devenir de esta cultura, parafraseando a J. López Quiroga y M. Lovelle en su estudio monográfico. ${ }^{25}$ Así, el reconocimiento de materiales tardíos en sitios como Penadominga (Bendollo), Santomé (Ourense) o São Brás (Paços de Ferreira, Frazão) fue evidente desde fechas muy tempranas, pero no llegaron a ser entendidos como un fenómeno particular al margen de la propia vida de los castros en la larga duración histórica. ${ }^{26}$

En este proceso historiográfico de reconocimiento de estas fases tardías fueron especialmente significativas las excavaciones llevadas a cabo en el yacimiento de Viladonga (Castro de Rei, Lugo). Este sitio, intervenido desde los años 70 por M. Chamoso Lamas, es uno de los castros más extensamente excavados no sólo del noroeste peninsular, sino de toda la Península Ibérica, ${ }^{27}$ lo que permitía por primera vez documentar grandes cantidades de material de los siglos IV al VI, si bien poco contextualizados. ${ }^{28}$ Tras un período sin intervenciones, se retomó la actividad durante los años 80 , no sólo revisando las antiguas excavaciones, sino ampliándolas hacia nuevos sectores. La presencia masiva de material romano tardío y de producciones post-romanas no pasó desapercibida y, así, distintos autores publicaron los primeros trabajos que planteaban de forma particular este fenómeno

24 Tranoy 1981, 419: "Al mismo tiempo que se constata un desarrollo de la propiedad agrícola organizada en torno a una villa, numerosos indicios muestran que los antiguos castros conocieron en el siglo III y en el IV un aumento de la actividad. Sin embargo, las dificultades son considerables, ya que numerosos castros son mal conocidos o incompletamente excavados" (trad. propia).

25 López Quiroga - Rodríguez Lovelle 1999, 355.

26 Dinis 1976; Cepeda 1993; Varela et alii 1997.

27 Vigil-Escalera - Tejerizo García 2014.

28 Arias - Durán 1996; Llana - Varela 2001. 
histórico. ${ }^{29} \mathrm{Si}$ bien en estas publicaciones existía todavía una fuerte dependencia de las narrativas de la larga duración dentro del mundo castreño, también se planteaba de forma particular el papel que estos sitios jugaron dentro del contexto del fin del Imperio romano, fundamentalmente como lugares de protección de la población en momentos de crisis política y económica. Incorporando lecturas de otros yacimientos similares en el contexto peninsular, comenzó a hablarse de "castros romanizados" tardíos,${ }^{30}$ lo que suponía, sin duda, un avance en la compresión de este fenómeno.

En gran medida, estas primeras lecturas sobre las ocupaciones tardías de los castros fueron muy dependientes de la documentación escrita, especialmente de la Crónica de Hidacio. ${ }^{31}$ Como es bien sabido, el obispo de Chaves escribió dos entradas en su obra que hacen referencia directa al sistema de poblamiento a principios del siglo V. Concretamente, en su entrada del año 411, Hidacio escribe: Spani per civitates et castella residui a plagis barbarorum per provincias dominantium se subiciunt servituti. ${ }^{32}$ Por su parte, en la conocida entrada del año 430, comenta:

Suevi, sub Hermerico rege, medias partes Gallaecia edepraedantes, per plebem, quae castella tutiora retinebat, acta suorum partimcaede, partim, captivitate, pacem quam ruperant, familiarum quae tenebantur, redhibitione restaurant. ${ }^{33}$

La referencia a estos castella tutiora asociados a una plebs ha hecho correr ríos de tinta sobre diversos temas como la estructuración social de la Gallaecia post-romana, la presencia de los contingentes suevos en la antigua provincia o el mantenimiento de una identidad galaico-romana. ${ }^{34}$ Pero, más relevante para nuestros propósitos, es el hecho de que a través de estas entradas se estableció una vinculación directa entre las ocupaciones tardías en los castros y estos castella tutiora de la tradición hidaciana. Así, la interpretación más recurrente para este tipo de asentamientos es la de espacios fortificados de defensa de la población galaico-romana frente a los ataques y razias de los suevos en un contexto de crisis y perturbación social durante los primeros compases de la quinta centuria. En palabras de J. López Quiroga y M. Lovelle:

En este marco, los castella tutiora podrían ser considerados como poblados fortificados de tipo defensivo aprovechando en algunos casos las defensas que presentan los castros, en otros reconstruyéndolas, o erigiendo nuevas fortificaciones, con población predominantemente galaico-romana-cristiana (aunque sin excluir la presencia de germanos muy romanizados en estos castella tutiora) ${ }^{35}$

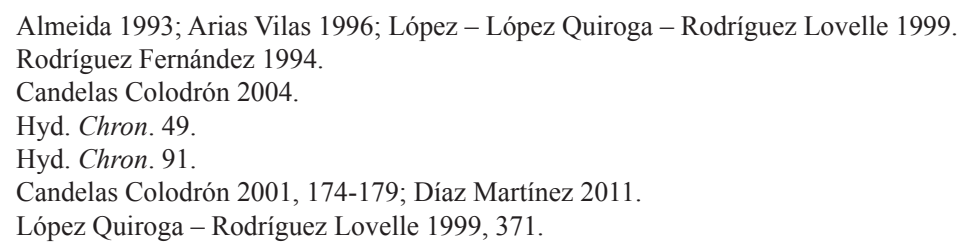


Esta interpretación, en sus aspectos básicos, es la que se ha mantenido hasta la actualidad y a través de la cual se han leído las nuevas excavaciones que se realizaban. Durante las últimas dos décadas se ha intervenido en algunos importantes contextos con ocupaciones tardías, como son los casos de Santomé, Elviña (A Coruña) o Torre Velha (Castro de Avelãs), por citar algunos de los más relevantes, que no sólo han aportado una información muy valiosa para identificar de forma más sólida este tipo de ocupaciones, sino también para diferenciarlas de otras fases dentro del mismo yacimiento. ${ }^{36}$ En otras palabras, poco a poco se entendía de forma compleja las biografías culturales particulares de cada yacimiento, ${ }^{37}$ sin dar por supuestas las largas duraciones en la secuencia de ocupación, detectando distintas fases y soluciones de continuidad y abandono. Por ejemplo, en el caso de Elviña, se ha podido identificar una secuencia de ocupación desde el siglo III a.C. hasta los siglos $\mathrm{V}$-VI con potenciales momentos de discontinuidad entre unas fases y otras. ${ }^{38}$ Algo similar ocurre en el caso de Santomé, en el que se pudieron identificar al menos dos o tres grandes fases de ocupación separadas por potenciales momentos de abandono. ${ }^{39}$ Sin embargo, la falta de publicaciones de secuencias de ocupación detalladas de todos estos contextos y de los materiales específicos asociados ha generado que las interpretaciones sobre este tipo de ocupaciones sigan encuadradas dentro de una corriente de larga duración histórica ${ }^{40}$ o como una respuesta coyuntural a la entrada de los pueblos germánicos, ${ }^{41}$ basadas en muchas ocasiones en una lectura errónea de las secuencias de ocupación.

En la última década esta situación se está corrigiendo progresivamente a medida que se realizan nuevas intervenciones, se publican nuevos contextos y se refinan las interpretaciones sobre estas ocupaciones tardías en los castros. Así, por citar algunos de los más relevantes, trabajos como el de A. Rodríguez Resino han tratado de sistematizar la información disponible sobre estos contextos, diferenciando entre castros con ocupaciones estables, castros vinculados con los castella tutiora hidacianos y castros relacionados con la existencia de villas en sus alrededores que "convive con el hábitat castreño hasta una época avanzada, y después acaba perviviendo como emplazamiento habitado del lugar, mientras el castro va quedando progresivamente despoblado". ${ }^{42}$ Por su parte, J. C. Sánchez Pardo realiza una tipología de castros diferenciando entre los enfocados al control territorial y los grandes recintos fortificados tipo oppida con un carácter multifuncional, destacando que "al analizar con más detalle el registro arqueológico disponible y, sobre todo, al tratar de contextualizarlo en el panorama más amplio del paisaje de la Galicia de los siglos IV-VI, encontramos una realidad más compleja, variada y dinámica", ${ }^{43}$ Finalmente, en un reciente trabajo en el contexto de la exposición "In tempore Sueborum", J. López Quiroga matizaba anteriores posiciones hacia un análisis multifuncional y de evolución interna de estos castros, dirigidos al control territorial

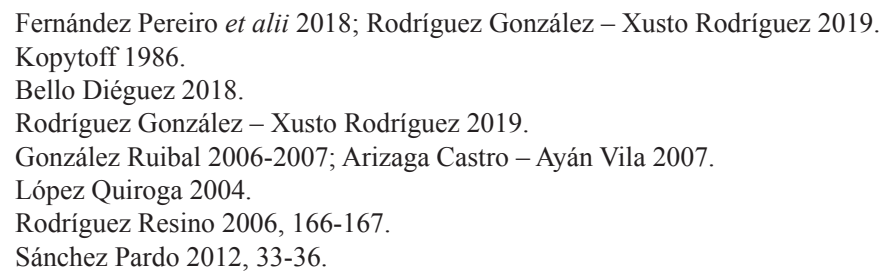


de las redes viarias y comerciales dentro de una perspectiva de larga duración dentro del período romano. ${ }^{44}$

Sin embargo, y a pesar de los enormes avances realizados al respecto desde el primer reconocimiento de este fenómeno arqueológico, siguen existiendo algunos problemas analíticos e interpretativos, sobre todo si se ponen en comparación con otro tipo de ocupaciones del norte peninsular o de Europa Occidental, ${ }^{45}$ como ya destacaron algunos autores en el pasado. ${ }^{46}$ Nos centraremos aquí sólo en algunos de los problemas analíticos, dejando para más adelante los problemas interpretativos.

El primero y más relevante de estos problemas es la propia indefinición de los contextos que se han introducido dentro de esta categoría de "castro romanizado" tardío. Como comentábamos al principio, la palabra "castro" es un concepto cargado de connotaciones que en muchas ocasiones genera problemas analíticos a la hora de caracterizar los contextos arqueológicos. De esta manera, la variabilidad a la hora de categorizar un "castro" puede llevar a ser excesivamente restrictiva, eliminando de la ecuación contextos con ocupaciones claramente tardías, o a ser excesivamente flexible, introduciendo yacimientos que no pertenecen a la misma tipología o que no muestran características similares. P. C. Díaz nos advierte de esta polisemia del término "castro":

Actualmente el concepto "castro", referido a la época romana, no se asocia con una morfología exclusiva. No es sólo un poblado reducido en sus dimensiones, rodeado de una muralla pétrea, habitualmente con un foso o una protección complementaria de piedras hincadas, ubicado en una elevación natural dominando el territorio. Hoy dicho concepto se extiende también a los castros o castella de llanura, relacionados con explotaciones agrarias, que, aunque presenten una morfología peculiar, se pueden asimilar al vicus de tradición romana, o a pequeños castros estratégicos con murallas de tierra, con finalidad tanto económica como defensiva, incluso fortalezas circunstanciales levantadas urgentemente para hacer frente al mismo problema de las invasiones, especialmente en nudos estratégicos de comunicaciones o en centros económicos importantes. No olvidemos que a veces la terminología, más que una diferencia morfológica, está definiendo categorías funcionales o administrativas. ${ }^{47}$

De lo que nos advierte P. C. Díaz es de la necesidad de clarificar el concepto de partida, de forma que se pueda particularizar el fenómeno y no introducir ruidos que distorsionen las posibles interpretaciones del registro arqueológico. Así, a través de una categorización muy laxa del concepto de "castro" se han introducido dentro de este tipo de ocupaciones tardías yacimientos como A Lanzada (Sanxenxo) o Castillós/Castillóns (Pantón), que no pertenecerían realmente a esta categoría de yacimiento a la que aquí nos referimos. El primero, si bien muestra ocupaciones claras de este momento de los siglos IV-VI, no se encuentra fortificado ni en una posición de altura relativa, siendo más probable que se trate de una aldea en abierto como otras localizadas en el norte peninsular y datadas

\footnotetext{
López Quiroga 2017, 165-168.

45 Brogiolo 2000; Quirós Castillo - Tejado Sebastián 2012; Tejerizo García - Canosa Betés 2018.

46 López Quiroga - Rodríguez Lovelle 1999.

47 Díaz Martínez 2011, 173.
} 
en los siglos V y VI. ${ }^{48}$ Por su parte, y a pesar del sugerente topónimo, las excavaciones de Castillós no muestran la presencia de un entorno fortificado con ocupaciones claras que se inserten en los siglos V-VI (si bien no hay duda de su adscripción a la cuarta centuria), siendo más probablemente, como ya se ha interpretado, "un aglomerado secundario galaicorromano, con una posible necrópolis asociada cerca de la Iglesia de Santiago". ${ }^{49}$ Otros yacimientos similares que han sido incluidos en algún momento dentro de esta categoría, pero que muestran la misma problemática, podrían ser los de Saceda (Cualedro), Fonte do Milho o, con más dudas incluso, Bretoña (A Pastoriza), todos ellos incluidos en la categoría de castros tardíos, pero de los que existen dudas, o bien sobre su ocupación durante este período (Saceda), o bien sobre su categoría como asentamiento fortificado (Fonte do Milho o Bretoña). ${ }^{50}$

El otro problema analítico de relevancia es la cuestión cronológica y estratigráfica. En diversas ocasiones, algunos yacimientos han sido incluidos dentro de esta categoría de castros tardíos por extensión de ocupaciones previas o por la presencia de ocupaciones posteriores, pero sin mostrar evidencias o contextos claros de los siglos IV-VI. En este sentido fue clave la emergencia de la categoría de "galaico-romano"(o el equivalente portugués "luso-romano") para aludir a este período histórico, que englobó, sin solución de continuidad, un amplio arco cronológico desde el siglo I al V. ${ }^{51}$ De esta manera, el uso de esta categoría como marcador cronológico generó diversas distorsiones, siendo la más importante la de entender que una ocupación "galaico-romana" de un sitio incluía de forma apriorística una ocupación durante todos esos siglos, aunque no hubiera evidencias empíricas explícitas al respecto. ${ }^{52}$

Un ejemplo de ello es el caso de Formigueiros (Sarria) (Fig. 1). Las excavaciones realizadas en este asentamiento dieron lugar a la documentación de una ocupación prehistórica clara con una reocupación posterior en época romana. La aparición de materiales supuestamente "paleocristianos", así como estructuras de peor factura por encima del poblamiento "castrexo", han hecho que diversos autores hayan incluido este sitio como parte del fenómeno de las ocupaciones tardías "galaico-romanas". 53 Sin embargo, la revisión del material arqueológico y la secuencia estratigráfica muestran que el asentamiento se abandonaría en torno a inicios del siglo II y que se reocuparía en época medieval o post-medieval. ${ }^{54}$ Un caso parecido sería el de Fazouro, en el que no se han documentado con seguridad contextos asociados a los siglos IV-VI, ${ }^{55}$ similar a lo que ocurriría en Armeá (Allariz) ${ }^{56}$ o el conocido sitio de San Cibrán de Lás, en el que, a pesar de tener asociado material altomedieval, todavía no han sido documentadas estratigrafías ni contextos claros de estos siglos. ${ }^{57}$ En otras situaciones, la simple presencia de materiales arqueológicos de los siglos IV-VI en el entorno de un topónimo asociado a "castro" es motivo suficiente para

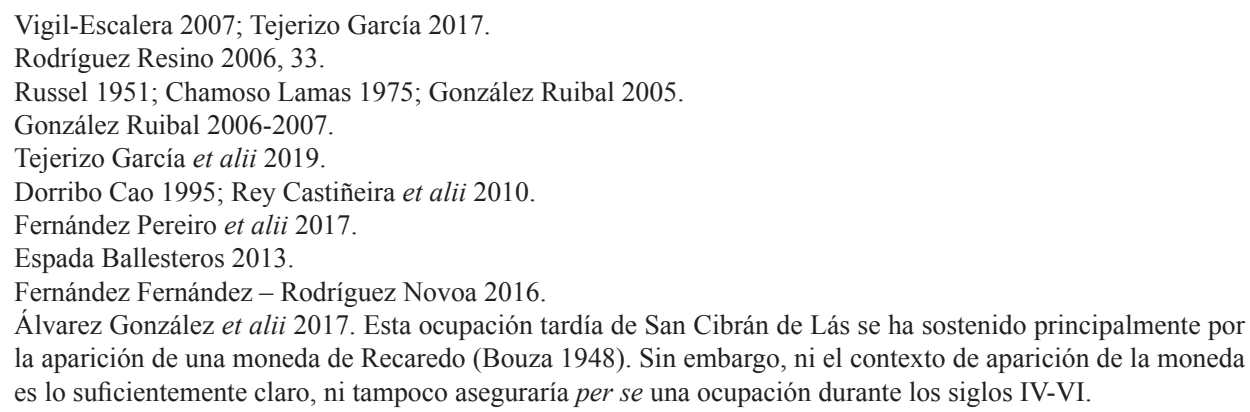


asegurar una ocupación durante este momento, a falta de más evidencias materiales, caso de sitios como, por ejemplo, el Castro de Devesa (Ribadeo) o el Castro de Cidá de San Millán (Cualedro). ${ }^{58}$ Esto no quiere decir que, efectivamente, estos sitios no tuvieran una ocupación durante este período, pero, de nuevo, las evidencias son lo suficientemente débiles como para plantear una duda razonable sobre los mismos a la espera de más excavaciones o de la publicación efectiva de los contextos.

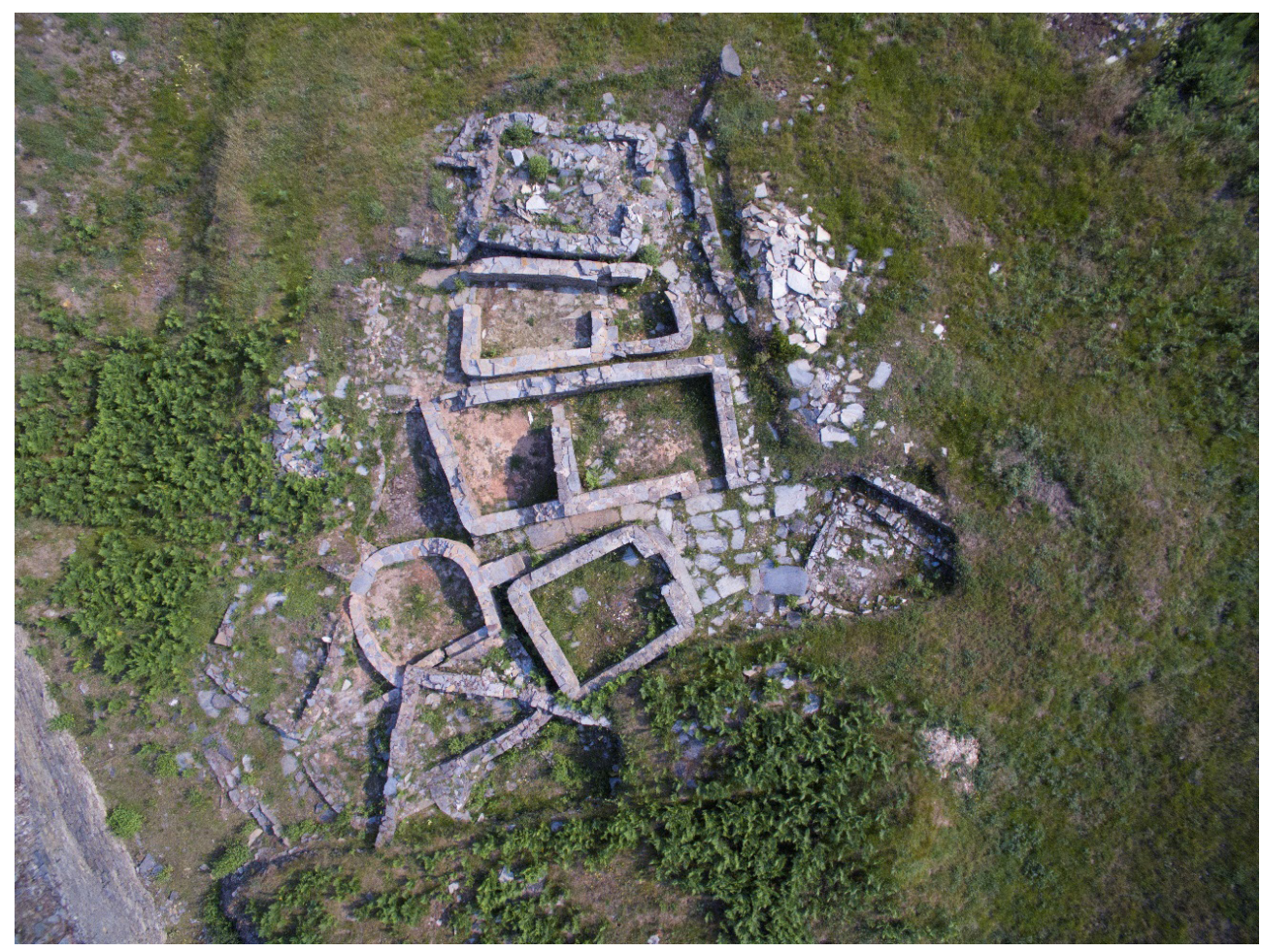

Figura 1. Zona central del castro de Formigueiros (fotografía de Manuel Franco)

\section{Los asentamientos fortificados en el noroeste peninsular. Construyendo la casa por los cimientos}

El breve análisis historiográfico previo ha mostrado la existencia de ciertas distorsiones a la hora de afrontar el fenómeno de las ocupaciones o reocupaciones de castros en época romana tardía que han penalizado la identificación e inclusión de diversos yacimientos dentro de esta categoría y, en consecuencia, las potenciales interpretaciones sobre los mismos. Valoradas estas cuestiones, entendemos que la mejor estrategia es comenzar la casa por los cimientos, reevaluando críticamente la información disponible en términos estratigráficos y contextuales de forma que se pueda vertebrar una propuesta de interpretación basada en la información empírica

58 Sánchez Pardo 2012, 37; Caselles López 2016, 23. 
efectivamente disponible. Así, el primer paso, entendemos, es clarificar el tipo de sitio al que se está haciendo referencia. En este sentido, y dadas las ambigüedades expuestas para el concepto de "castro", optaremos por la de asentamientos fortificados ocupados entre los siglos IV-VI, definidos como asentamientos de carácter estable (con ocupaciones superiores a las dos generaciones) y cerrado, es decir, inscrito dentro de un espacio limitado (normalmente por murallas) en una altura relativa con clara intencionalidad de control visual del territorio inmediato así como de establecerse como un nodo central visible del paisaje. ${ }^{59}$

Esta conceptualización tiene dos ventajas: una analítica y otra cronológica. La ventaja analítica es que permite diferenciar este tipo de asentamientos de otros contemporáneos, como por ejemplo los asentamientos abiertos tipo aldeas o granjas, así como las villas tardoimperiales. ${ }^{60}$ Del mismo modo, la vinculación de estos asentamientos fortificados con un período determinado, los siglos IV-VI, permite particularizar un contexto histórico frente a otros, cuyas explicaciones pueden ser totalmente distintas. En este sentido, nos referimos aquí a lo que se ha venido a llamar "castillos de primera generación", precisamente vinculados a estos momentos finales del Imperio romano y la emergencia de los primeros siglos altomedievales, en relación con unos "castillos de segunda generación" asociados al contexto de transformación social de los siglos VII y VIII, fundamentalmente. ${ }^{61}$ De hecho, la evidencia empírica disponible muestra de forma reiterada que existe una evidente solución de continuidad entre una fase y otra en la ocupación de este tipo de asentamientos. $^{62}$

Una vez establecida esta categorización, el segundo paso ha sido la recopilación de toda la evidencia empírica disponible sobre los asentamientos que efectivamente responden a ella y someterla a un análisis crítico, trabajo que todavía está en marcha, pero del que aquí presentamos una primera aproximación. Así, partimos de una primera recopilación de todos los asentamientos que habían sido considerados dentro de la categoría de castros tardíos en la bibliografía o que mostraban evidencias de una ocupación entre los siglos IV-VI. En este sentido, fueron extremadamente útiles los trabajos de síntesis de J. López Quiroga y M. Lovelle, Á. Rodríguez Resino o J. C. Sánchez Pardo, así como un reciente Trabajo Final de Máster realizado por I. Caselles, que nos permitieron recopilar un primer listado de yacimientos. ${ }^{63}$ Asimismo, se incluyeron en esta primera recopilación también aquellos yacimientos que han sido objeto de excavaciones recientes, así como los que potencialmente podrían señalar una presencia de ocupación durante los siglos considerados. En este sentido, dos son los marcadores arqueológicos fundamentales que permiten sugerir una ocupación durante los siglos IV y VI cuando se localizan (efectivamente) en asentamientos fortificados. En primer lugar, la presencia de cerámicas asociadas a los últimos ciclos de sigillata, fundamentalmente terra sigillata Hispánica Tardía (TSHT), terra sigillata Africana del período, la llamada sigillata clara D o producciones grises tardías. ${ }^{64}$ En segundo lugar, otro marcador que ha resultado especialmente útil para la detección de estos yacimientos es la presencia de numerario del siglo IV, un aspecto que se ha revelado

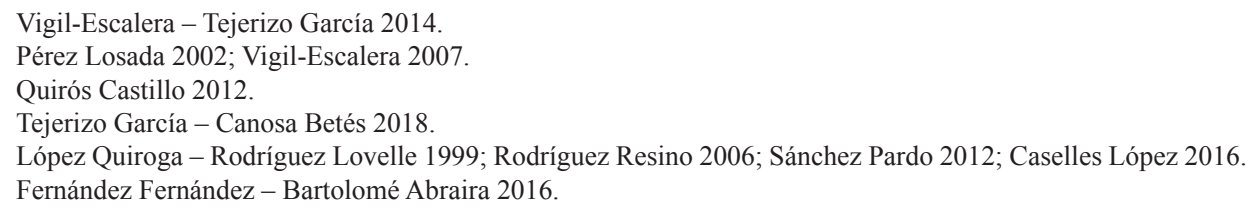


como muy característico de este tipo de contextos en el noroeste peninsular. ${ }^{65}$ Como se ha podido comprobar en yacimientos como Viladonga (Fig. 2), el atesoramiento y utilización del numerario de bajo valor de los siglos III y IV tiene una pervivencia larga en el tiempo, llegando incluso a la sexta centuria. ${ }^{66}$ Esto lo convierte en un buen marcador para la detección de este tipo de asentamientos fortificados, pero, sin embargo, precisa de una necesaria crítica estratigráfica para datar los contextos.

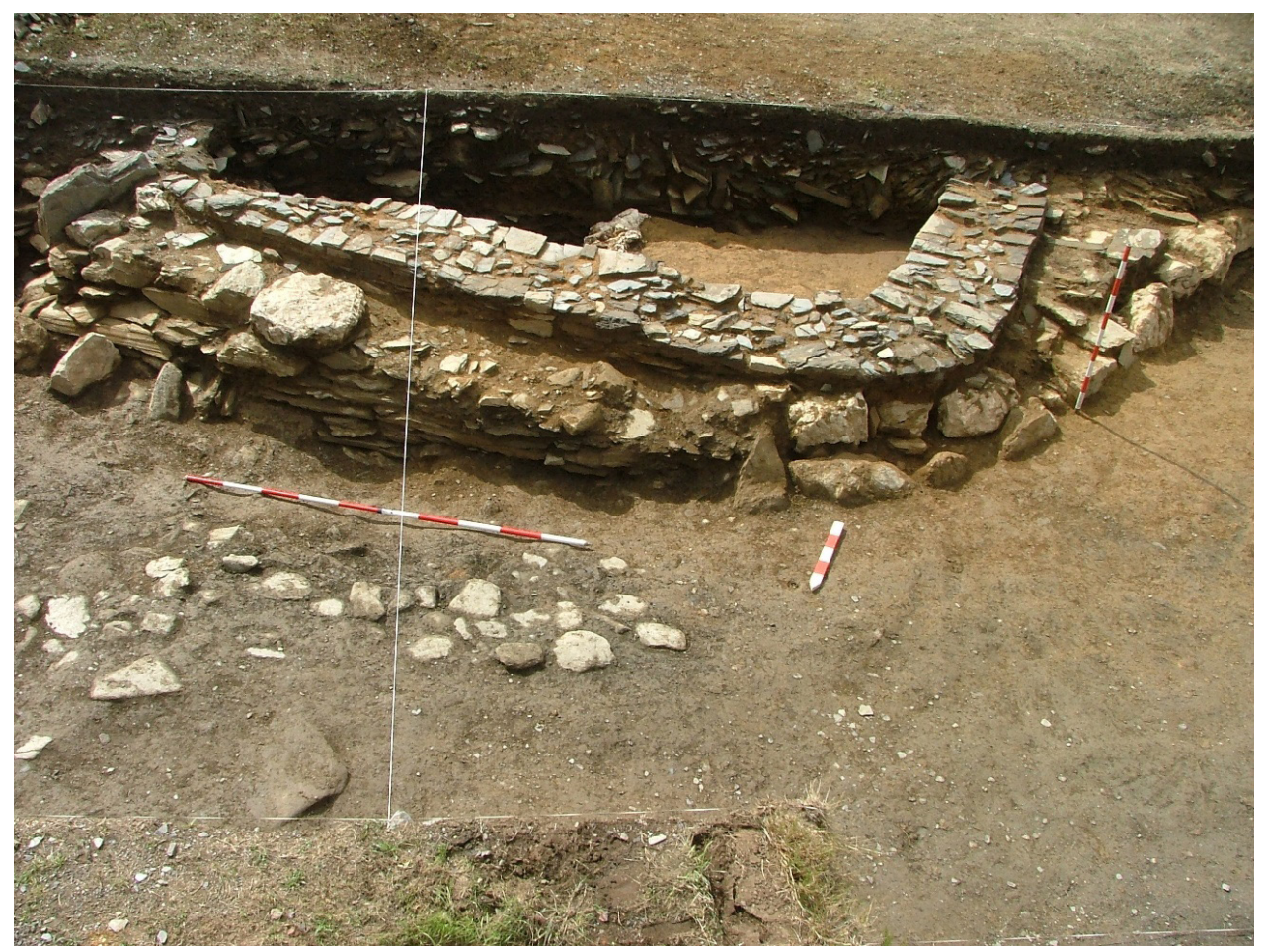

Figura 2. Estructura excavada en Viladonga donde se observa la presencia de, al menos, dos grandes fases (fotografía de AXA Arqueología)

Una vez elaborada una primera lista de todos los yacimientos con posibles evidencias de los siglos IV-VI, y teniendo en cuenta las precauciones anteriormente comentadas, se realizó una lectura crítica de toda la información disponible para cada sitio, valorando la procedencia de las evidencias, su caracterización contextual y la valoración tipológica del sitio. De esta manera, se han recopilado por el momento un total de 43 asentamientos fortificados, de los cuales 14 todavía ofrecen dudas a la espera de una revisión más exhaustiva, y cuatro podrían categorizarse como "lugares centrales" del período ${ }^{67}$ pero que mostrarían las mismas características de un asentamiento fortificado, que serían Astorga, Braga, Lugo y Vigo, en tanto que

\footnotetext{
Cepeda 1988.

Tejerizo García et alii 2019; Amorós Ruiz - Doménech Belda 2020.

Martínez Jiménez - Tejerizo García 2015.
} 
posible emporium..$^{68} \mathrm{La}$ información resultante se resume en la figura siguiente (Fig. 3) y en la tabla que puede encontrarse al final del artículo (Tabla 1).

Del conjunto de estos datos cabe señalar varias cuestiones de interés como primera aproximación para futuros estudios que complementen la información aquí reseñada. En primer lugar, la distribución espacial de los yacimientos, en la que se observan varios núcleos de concentración así como vacíos territoriales. En cuanto a estos últimos, cabe destacar la relativa ausencia de asentamientos fortificados en el cuadrante noroccidental. Esto puede ser debido, en primera instancia, a una falta de información arqueológica precisa sobre este territorio, o incluso a las propias características geográficas del entorno, con la presencia de espacios más amesetados que harían más complicada la opción de ocupar un asentamiento fortificado durante este período. Del mismo modo, este vacío podría obedecer a factores de tipo económico y social, con una potencial pervivencia en estos territorios, al menos hasta mediados de la quinta centuria, de los asentamientos de tipo abierto vinculados a las villas tardoimperiales de la zona,${ }^{69}$ así como de una mayor proliferación de las aldeas y granjas altomedievales, como ha sido sugerido en otros estudios. ${ }^{70}$

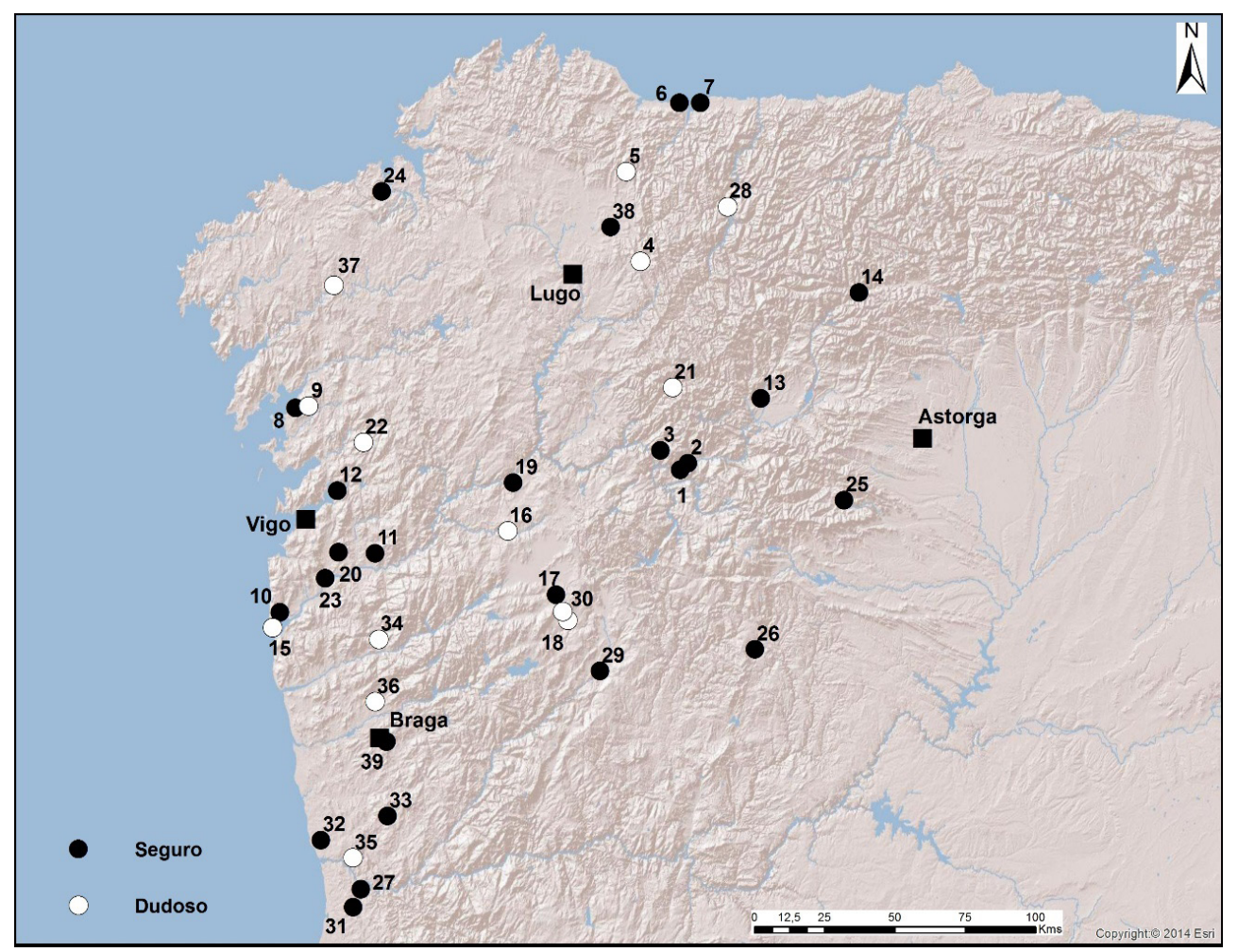

Figura 3. Asentamientos fortificados en el noroeste peninsular (siglos IV-VI) (figura realizada por los autores)

\footnotetext{
Fernández Fernández 2014.

Pérez Losada et alii 2008.

Tejerizo García 2020.
} 
Por el contrario, se observan varias zonas de concentración de gran interés. Concretamente, habría que destacar tres. La primera sería, en términos amplios, la zona de costa, con la proliferación de asentamientos fortificados sobre todo en el norte de Portugal, las actuales Rías Baixas y, en menor medida, la costa norte, tanto atlántica como cantábrica. Especificando más dentro de esta zona de costa, cabe destacar la proliferación de este tipo de asentamientos en los dos principales lugares centrales del suroeste, Vigo y Braga. Sobre todo en el primer caso, la concentración de asentamientos fortificados de los siglos IV-VI parece ser especialmente intensa. Como luego desarrollaremos en detalle, y como han señalado otros autores ${ }^{71}$ la vinculación de esta red de asentamientos fortificados con el mantenimiento del comercio marítimo identificado en Vigo y otras ciudades de la costa es una hipótesis muy sugerente que luego retomaremos. Esta relación con el comercio podría estar también en la base explicativa de la tercera de las concentraciones detectadas, como sería la zona del sureste y, más concretamente, el área de la llamada depresión meridiana y el del curso del río Sil. Ambos espacios, de hecho, ya han sido destacados en otros estudios como lugares de concentración de este tipo de asentamientos. ${ }^{72}$ No deja de ser casual que estas dos sean las vías, junto con la marítima, más lógicas de acceso al noroeste peninsular. En cualquier caso, y como también ha sido puesto de relieve en otros estudios, es muy explícita la vinculación de este tipo de asentamientos con la antigua red viaria romana $\mathrm{y}$, sobre todo y de forma complementaria, con los cursos de los principales ríos. ${ }^{73}$

Con respecto a los yacimientos específicos cabe hacer algunas valoraciones generales. En primer lugar, la evidente parquedad de la información y, en muchos casos, su dudosa naturaleza. Únicamente algunos de los yacimientos han sido objeto de excavaciones de cierta extensión, si bien la mayoría son relativamente antiguas, caso de sitios como Bretoña, S. Brás o Falperra. Sólo en unos pocos casos -Viladonga, Santomé, La Muela (Villablino), Valencia do Sil (Vilamartín de Valdeorras), Torre Velha, Crestuma (Vila Nova de Gaia), Budiño (O Porriño) y Alobre (Vilagarcía de Arousa)- las excavaciones han sido más recientes, e incluso, para estas intervenciones la publicación de los resultados es, a día de hoy, muy parcial y con una importante escasez de contextos estratigráficos efectivamente analizados, salvo casos muy puntuales como Viladonga o Torre Velha. ${ }^{74}$ Así, en la mayoría de los asentamientos fortificados la información disponible queda reducida a noticias de hallazgos o referencias a materiales escasamente contextualizados, como ocurre en sitios como Penadominga o Cida de San Millán. ${ }^{75}$ Más aún, la escasez de dataciones radiocarbónicas realizadas y publicadas no permite aquilatar con un cierto grado de rigurosidad las secuencias de ocupación de los asentamientos, lo que ha repercutido en una utilización muy laxa de estas secuencias a la hora de interpretar los yacimientos. ${ }^{76}$ Afortunadamente, esta tendencia está cambiando progresivamente y contamos cada vez con más dataciones que permiten una evaluación crítica de algunas secuencias, como ocurre en Viladonga, Budiño, Valencia do Sil o Santomé. ${ }^{77}$

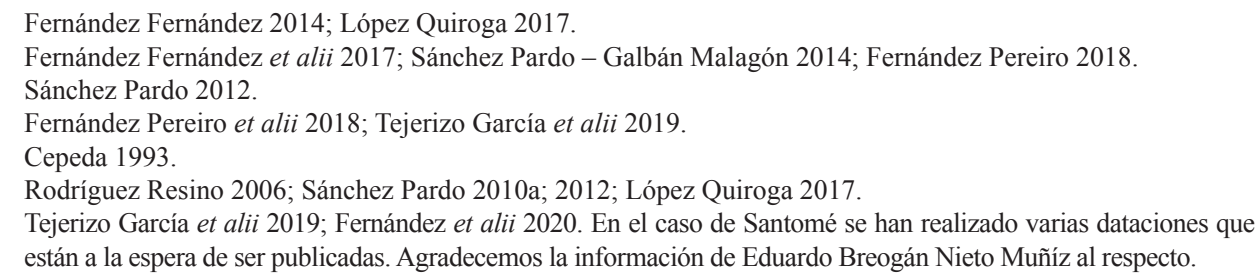


De esta manera, y gracias tanto a las nuevas excavaciones como a las aportaciones historiográficas más recientes anteriormente comentadas, contamos ya con algunos contextos específicos relativamente bien conocidos que permiten un acercamiento más complejo a este tipo de asentamientos en el noroeste peninsular. Presentaremos aquí brevemente algunos aspectos de los tres más relevantes (Viladonga, Santomé y Valencia do Sil) que nos permitirán posteriormente sintetizar las principales características de estos contextos, así como unas primeras hipótesis interpretativas.

Ya comentamos anteriormente la importancia historiográfica de Viladonga, un asentamiento fortificado situado en las cercanías de la ciudad de Lugo. En una reciente revisión exhaustiva de los conjuntos cerámicos y de la estratigrafía de parte de las últimas campañas de excavación, ${ }^{78}$ se pudo establecer una propuesta de secuencia de ocupación del yacimiento en la que destacaba un momento de abandono entre el siglo II y la primera mitad del siglo IV, con una reocupación posterior hasta los primeros compases de la sexta centuria. Estas dos fases de ocupación se atestiguaban de forma clara tanto en los contextos (con dos tipos de conjuntos cerámicos claramente diferenciados) como en la estratigrafía de las unidades domésticas subrectangulares excavadas en las últimas campañas, que mostraban no sólo estructuras inferiores de formato circular, sino la reutilización masiva de material en los muros, incluyendo molinos de mano. Esta reocupación tardía supuso una reestructuración completa del yacimiento, así como refacciones en la muralla, producto de un abandono prolongado en el tiempo. Un aspecto de enorme interés en el sitio derivado del análisis cerámico es la presencia de una gran variedad de producciones dentro del intervalo entre los siglos IV-VI, lo que señalaba a Viladonga como un centro de consumo de cierto estatus, igualmente mostrado por la enorme cantidad de numerario y tesorillos localizados en el sitio. ${ }^{79}$

Otro de los yacimientos que vamos a destacar en este trabajo es el conjunto arqueológico de Santomé (Fig. 4), situado a dos kilómetros de la ciudad de Ourense. Este asentamiento ha sido objeto de estudio de la arqueología durante los últimos 50 años. ${ }^{80}$ Todas estas intervenciones han dado importantes resultados que permiten conocer la singularidad de los espacios domésticos dentro de los asentamientos fortificados entre los siglos IV-V. Sin embargo, a pesar de que la gran cantidad de material recuperado de este asentamiento se puede adscribir a los momentos de finales del Imperio y de que existe un cambio en la reorganización del espacio, este lugar sigue siendo uno de los ejemplos más reconocidos de la "larga ocupación". A partir de la revisión que hemos realizado en los últimos años de las campañas de excavación de los años 80, logramos entender la secuencia estratigráfica de buena parte de las estructuras situadas en la zona noroeste del yacimiento. En este sentido, se aprecian dos fases diferenciadas: una fase correspondiente a las estructuras bajoimperiales en los límites del mundo medieval y otra más antigua, probablemente del cambio de era o altoimperial. En el caso de la fase tardorromana, que es la que nos interesa para este estudio, los materiales son la más clara evidencia de una ocupación entre los siglos IV y V, con restos de cerámica engobada de producción lucense vinculada a otros fragmentos tipológicos perfectamente encuadrables en estas fechas como la terra sigillata hispánica tardía procedente de los talleres de la meseta, o

\footnotetext{
78 Tejerizo García et alii 2019.

79 Tejerizo García et alii 2018; Tejerizo García et alii 2019.

80 Rodríguez González - Xusto Rodríguez 2019.
} 
terra sigillata africana clara $\mathrm{D}$, junto a vidrios que conviven en estas centurias, metales como cuchillos tipo Simancas y monedas de cronologías tardorromanas que probablemente tengan una pervivencia posterior a los siglos de emisión, como sucede en otros yacimientos del entorno. ${ }^{81}$

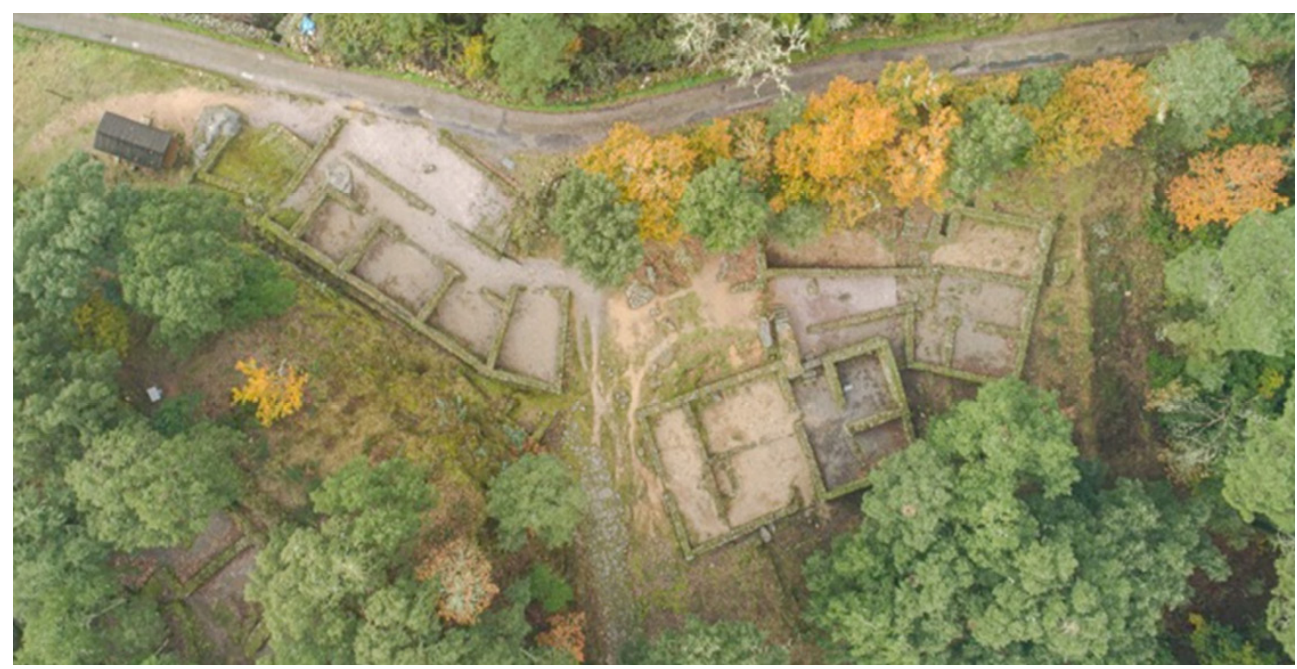

Figura 4. Sectores 1 y 2 de Santomé (foto cedida por Eduardo Breogán Nieto Muñíz)

No obstante, este cambio se aprecia también en la materialidad inmueble, ya que se produce un cambio brusco en la concepción espacial que reordena el asentamiento, eliminando, hasta niveles de cimentación, estructuras previamente construidas y vinculadas a materiales asociados al cambio de era, ${ }^{82}$ y sobre los que se nivelan y construyen las estructuras actualmente visibles en el yacimiento de la fase "tardía". Por otro lado, la información más concreta y que afianza nuestra hipótesis interpretativa sobre el cambio y la pervivencia de la ocupación de Santomé durante los siglos IV y V se documenta en la zona recientemente excavada en la campaña de 2019. Esta intervención, a través de una secuencia estratigráfica más completa y moderna, unida a diferentes análisis de C14, ha podido determinar que en el área de la ladera sur del emplazamiento también existió una utilización del espacio como lugar funcional de herrería a partir del siglo $\mathrm{IV}^{83}$ y que probablemente se extendiera hasta finales del siglo $\mathrm{V}$.

El último yacimiento al que haremos referencia es el de Valencia do Sil (Fig. 5), situado en un entorno de altura relativa con respecto al curso del río Sil. Si bien este yacimiento era conocido desde inicios del siglo $\mathrm{XX}$, no fue hasta los años 60 y 70 que se excavó extensamente. ${ }^{84}$ Desde 2018 hemos podido realizar distintos trabajos de excavación que han ampliado los antiguos sondeos, principalmente en torno a una gran unidad doméstica, así como en otros espacios

\footnotetext{
81 Tejerizo García et alii 2019.

82 Rodríguez González 1984.

83 Nieto Muñíz 2019.

84 Tejerizo García et alii 2019.
} 
aledaños que podrían estar vinculados a tareas de producción o almacenamiento de la producción, al menos en las últimas fases antes de su abandono. Llama la atención el grado de desarrollo estructural de los edificios, con la presencia no sólo de suelos de opus signinum, sino también de estucados pintados en las paredes, especialmente raros en este tipo de contextos. Un desarrollo que implicó también una organización muy compleja del espacio del yacimiento a través de distintas plataformas excavadas en la roca natural que supusieron un enorme esfuerzo de acondicionamiento del espacio. El análisis estratigráfico, sumado a las dataciones radiocarbónicas, nos han permitido sugerir, al igual que en los otros dos casos, dos grandes fases de ocupación con una importante cesura entre ellas, situándose la segunda fase entre mediados de la cuarta centuria y mediados o finales de la quinta centuria, con posibilidades, todavía muy hipotéticas basadas en materiales descontextualizados, de prolongarse hasta la sexta centuria. Cabe destacar que en el entorno de este sitio se localizan otros importantes asentamientos fortificados, como Santa María de Mones (Petín) o Penadominga, lo que podría llevar a sugerir la presencia de una red de control en torno al propio río Sil. ${ }^{85}$

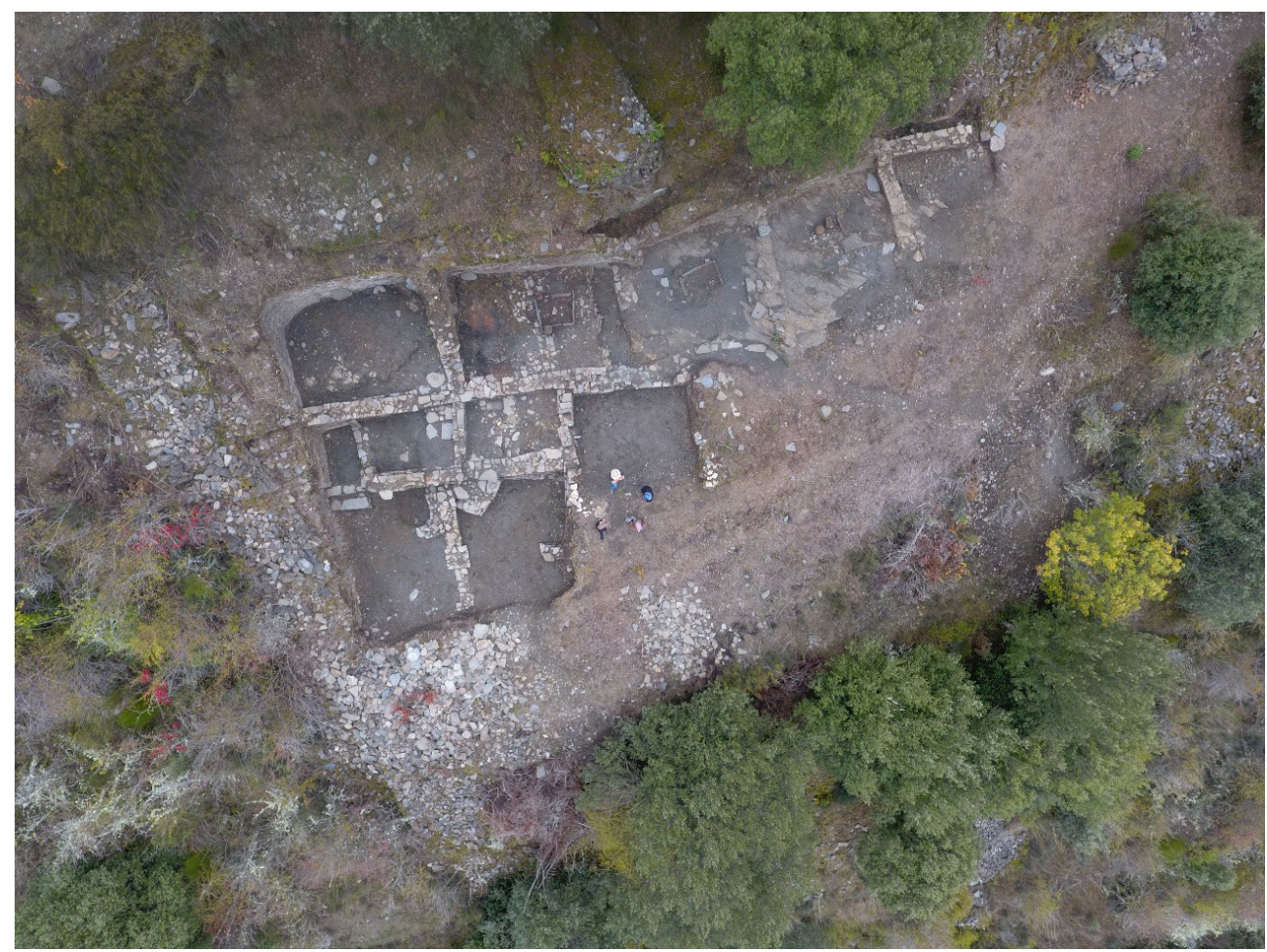

Figura 5. Unidad doméstica excavada en Valencia do Sil (fotografía de los autores)

$85 \quad$ Fernández Pereiro et alii 2017. 


\section{Algunas consideraciones interpretativas sobre los asentamientos fortificados de los siglos IV-VI en el noroeste peninsular}

Si bien se trata de un trabajo todavía en marcha, una primera revisión crítica global de los asentamientos fortificados con evidencias de ocupación entre los siglos IV y VI permite sugerir diversas ideas e hipótesis interpretativas del fenómeno en su conjunto, sobre todo puesto en relación con los contextos similares conocidos para otros entornos geográficos. Aquí delinearemos algunas de las más significativas.

En primer lugar, parece evidente, como ya afirmaron los primeros autores que reconocieron el propio fenómeno en los años 80, que la ocupación de este tipo de asentamientos a finales del Imperio romano y durante, al menos, la emergencia del reino suevo es un fenómeno muy extendido en el noroeste peninsular. A falta de completar un cuadro de seguro más complejo, al menos una treintena de yacimientos muestran evidencias claras de ocupación durante este período. Más aún, las características materiales de aquellos casos en los que disponemos de un grado mayor de información (Viladonga, Castro Ventosa, Valencia do Sil, Santomé) evidencian entornos estables con una clara naturaleza doméstica, señalada a través de la presencia de edificios como el área doméstica de Valencia do Sil o de Santomé. ${ }^{86}$ Así lo muestran las numerosas unidades domésticas de este período excavadas en Viladonga, algunas de las cuales han deparado tesorillos monetarios, elementos de adorno personal, así como materiales como los pondera textiles, ${ }^{87}$ que señalarían, sin lugar a dudas, una compleja organización social y económica. En el caso de Valencia do Sil, el análisis de la fauna localizada en el sitio muestra la presencia de un consumo (y, por lo tanto, una producción) de carne y productos animales muy diversificado. ${ }^{88}$ Igualmente, la potencial presencia de un horno para la fabricación de vidrio en el yacimiento de Castro Ventosa atestiguaría procesos tecnológicos complejos operando dentro de este tipo de asentamientos. ${ }^{89}$ En resumen, se trata de espacios destinados a una ocupación estable en el tiempo, en los que posiblemente se desarrollaran la mayor parte de las actividades de producción y reproducción de las sociedades que los habitaron.

Dicha estabilidad se muestra, además, en sus secuencias de ocupación. Si bien todavía no existe una información estratigráfica fiable para todos los yacimientos aquí considerados, aquellos con mejores datos muestran ocupaciones desde, aproximadamente, mediados de la cuarta centuria hasta finales de la quinta, si no incluso dentro de la sexta. Aunque no se puede descartar, por la escasez de información estratigráfica, la presencia de ocupaciones durante la tercera centuria, ninguno de los yacimientos presenta con seguridad contextos de este momento, más allá de materiales cerámicos de dataciones muy laxas (como la cerámica común romana, si bien siempre acompañada de TSHT que indica cronologías posteriores a la tercera centuria) o de numerario de ese período, siempre presente en contextos muy posteriores, como se demuestra en los casos de Viladonga, Santomé o Valencia do Sil. En cualquier caso, y a la espera de tener secuencias estratigráficas bien definidas, lo que se muestra de forma clara es la estabilidad en la ocupación de estos sitios,

\footnotetext{
Rodríguez González - Xusto Rodríguez 2019; Tejerizo García - Rodríguez González 2019.

Lage Pillado 2004; Durán Fuentes 2009; Pérez Rozas 2017.

Fernández Fernández 2020.

89 Díaz Álvarez - Garín 1999.
} 
siempre superiores a las tres o cuatro generaciones. La naturaleza de estabilidad doméstica, así como la propia materialidad de los asentamientos, lleva a poner en tela de juicio aquellas explicaciones para las que estos serían una respuesta coyuntural de poblaciones en peligro a un momento de inestabilidad. Más aún, y como ocurre en otros territorios peninsulares, la distribución espacial de estos asentamientos puede cuestionar los relatos explicativos en términos de limes y de fronteras, ${ }^{90}$ al menos para la gran mayoría de estos sitios. ${ }^{91}$ ¿Significa esto que hay que desechar el modelo explicativo de los castella tutiora de la tradición hidaciana? La respuesta, a tenor de la evidencia disponible, es que no, al menos parcialmente. Frente a una interpretación unicausal y determinista, lo que muestran los datos empíricos es, como afirmaba J. C. Sánchez Pardo y al que se hacía referencia anteriormente, "una realidad más compleja, variada y dinámica". Y para definir con un cierto grado de complejidad esta realidad habría que tener en cuenta, como punto de partida interpretativo, varias cuestiones.

La primera es que nos encontramos con un fenómeno variado que, como advierte P. C. Díaz, "debe ser valorado de manera distinta en función del contexto geográfico particular". ${ }^{92}$ Tomando en consideración las categorías elaboradas por algunos autores, ${ }^{93}$ podemos distinguir al menos tres modelos de asentamientos fortificados dentro del conjunto aquí analizado. Al primero, definido como lugares centrales dentro de redes jerárquicas de asentamientos, pueden corresponder sitios como Castro Ventosa y Falperra, que muestran elementos materiales de gran estatus que podrían vincularse con agentes sociales de alto poder económico con una potencial conexión con los poderes estatales del momento. La cercanía de Falperra a Braga se puede asociar de forma directa con el despliegue simbólico del poder suevo, mientras que Castro Ventosa pudo actuar como un lugar central de control en las periferias territoriales del reino. ${ }^{94} \mathrm{Un}$ segundo modelo responde a centros regionales de poder, potencialmente vinculados a élites territoriales dedicadas a controlar la producción del entorno, como podría ocurrir en los casos de Viladonga, Crestuma o la Torre Velha. El tercer modelo es el de pequeñas redes de asentamientos para el control de los espacios locales o de pequeña escala. Como ya comentamos, este modelo puede ser el que explica el conjunto de asentamientos localizados en la depresión meridiana, así como en la comarca de Valdeorras, dirigidos al control de los accesos al noroeste peninsular. Derivado de este modelo, pero como característica particular de este territorio, se podrían entender todos los asentamientos fortificados localizados a lo largo de la línea de costa o en el entorno inmediato de Vigo, dedicados hipotéticamente al control del comercio marítimo tanto en su recorrido hacia el norte como al interior a través de los pasos fluviales.

Un aspecto del fenómeno de los asentamientos fortificados del noroeste que contrasta con otros territorios del norte peninsular es su temprana cronología de ocupación. A tenor de lo que sabemos de los contextos mejor datados de la meseta

\footnotetext{
Palol 1969; Ariño Gil - Díaz Martínez 2014.

Tejerizo García - Canosa Betés 2018.

Díaz Martínez 2011, 173.

Tejerizo García - Canosa Betés 2018.

Balboa et alii 2003; Fontes 2017.
} 
norte, como El Castillón, ${ }^{95}$ El Cristo de San Esteban, ${ }^{96}$ Navasangil ${ }^{97}$ o Dehesa de la Oliva, ${ }^{98}$ parece que este fenómeno de ocupación de asentamientos fortificados se inicia a mediados del siglo $\mathrm{V}$, en vez de casi una centuria antes como parecen indicar las cronologías en los asentamientos del noroeste peninsular. Sin embargo, creemos que la explicación histórica y social es similar, esto es: los asentamientos fortificados como una respuesta de las élites territoriales tardoimperiales a la desestructuración de las bases económicas sobre las que se sostenían. ${ }^{99}$ La diferencia radicaría en la temporalidad de este proceso que, como sabemos precisamente a través de la documentación escrita como la del obispo de Chaves, sería potencialmente más temprana en los territorios del norte y noroeste peninsular, a raíz de la inestabilidad política que supondría la acción de las élites militares de suevos, vándalos y alanos ya desde finales del siglo IV e inicios del siglo $\mathrm{V}$ y, sobre todo, la respuesta de las élites territoriales tardoimperiales, que verían amenazadas sus formas tradicionales de poder y control. ${ }^{100}$ Como se afirma en otro trabajo:

The Germanic invasions played a role not only in military terms but also ideologically, creating a new political status quo which post-Roman elites had to conform. The occupation of some of these hill-forts may have initially responded to a perceived danger, whether imaginary or real. ${ }^{101}$

En este sentido, efectivamente, se podría hablar de algunos de estos asentamientos como de castella tutiora, en tanto que espacios de habitación y de control territorial de las élites tardoimperiales. Desde una lectura arqueológica, se podría matizar el sentido que Hidacio imprime al concepto de plebs asociado a los castella. El uso que de este término hace el obispo de Chaves buscaría vincular a las gentes que habitaban estos castros con estratos inferiores de la sociedad, conceptualmente con una idea de "comunidad" con la que él mismo se identificaría pero a cuyo estrato no pertenecería. Sin embargo, no hay que olvidar que el propio Hidacio, en tanto que miembro de la élite tardoimperial, buscaría proteger los intereses de su clase en un momento de profundo cambio estructural del poder. ${ }^{102}$ Un interés que le llevaría a identificar a su clase particular con el conjunto del pueblo galaico-romano $\mathrm{y}$, en consecuencia, a los habitantes de estos asentamientos fortificados, que no corresponderían a todo el conjunto de la sociedad del momento, sino únicamente a una parte de alto estatus dentro de la misma, como se deriva de la existencia de otros asentamientos contemporáneos tipo aldeas y granjas que poco a poco se están identificando en el registro arqueológico. ${ }^{103}$ En palabras de P. C. Díaz, "por lo tanto, el hábitat tipo 'castro' puede no ser, según se avanza en la historia del periodo romano en Gallaecia, sino una forma más del poblamiento del noroeste hispano". ${ }^{104}$

\footnotetext{
95 Sastre Blanco et alii 2014.

96 Domínguez Bolaños - Nuño González 2014.

97 Caballero Arribas - Peñas Pedrero 2012; Tejerizo García - Vigil-Escalera 2017.

98 Vigil-Escalera 2012.

99 Tejerizo García - Canosa Betés 2018.

100 Halsall 2014.

101 Tejerizo García - Canosa Betés 2018, 318.

102 Candelas Colodrón 2001; 2004; Díaz Martínez 2011.

103 Tejerizo García 2020.

104 Díaz Martínez 2011, 173.
} 
Esto nos llevaría a considerar otro aspecto relacionado comúnmente con los asentamientos fortificados tardíos, como es la relación establecida entre estos y las villas tardoimperiales, lo que se conoce como la "dualidad villa-castro", ${ }^{105}$ que otros autores establecen desde períodos anteriores. ${ }^{106}$ En este sentido, los datos sobre las fases finales de las villas tardoimperiales en el noroeste peninsular (salvo casos muy particulares, sobre todo en los lugares de costa ${ }^{107}$ son todavía muy escasos como para poder establecer hipótesis mínimamente fiables. ${ }^{108}$ Sin embargo, cabe señalar que esta dualidad se apoya en el presupuesto de que los asentamientos fortificados tardíos y las villas tardoimperiales son contemporáneas, muchas veces basado en la cercanía geográfica de los dos tipos de asentamientos, como ocurre en Viladonga y la cercana villa de Doncide, ${ }^{109} \mathrm{o}$ en la presencia de una villa en un entorno con topónimos tipo "castro", como en Castillós. Sin embargo, todavía no hay evidencias estratigráficas suficientes como para establecer la contemporaneidad en la ocupación de ambos tipos de entornos y, por lo tanto, en la sustentación de las interpretaciones de la dualidad villa-castro. En otras palabras, hace falta más evidencia para poder realizar hipótesis al respecto de las potenciales conexiones sociales y económicas entre los dos tipos de asentamientos o, por el contrario, la sustitución de las funciones de uno por el otro.

En cualquier caso, las secuencias de ocupación efectivamente presentes en estos sitios, a tenor de la evidencia empírica y estratigráfica, desbordarían los marcos cronológicos e interpretativos de los castella tutiora. Como comentamos, los yacimientos con la mejor información disponible mostrarían momentos de abandono de la segunda mitad del siglo $\mathrm{V}$ o incluso inicios del siglo VI, que nos insertan ya en un contexto de plena implantación y expansión del estado suevo: hay que recordar, por ejemplo, que es en 467 cuando se data el saqueo de Conimbriga por los suevos. De esta manera, lo que señalaría la evidencia empírica es que la naturaleza y función política de los asentamientos fortificados se verían modificadas a lo largo del tiempo. En este sentido cabría interpretar parte de estos asentamientos fortificados dentro de las lógicas de las avenues of collaboration propuestas por S. Castellanos e I. Martín Viso entre las élites territoriales y el poder estatal ${ }^{110} \mathrm{o}$, como ya se ha sugerido para Falperra o Castro Ventosa, como iniciativas mismas de las élites estatales o de las potentes élites territoriales en su posicionamiento dentro del proyecto de estado suevo. En resumen, y a falta de estudios más detallados tanto de los casos particulares como de los distintos territorios, la naturaleza de estos sitios como castella tutiora parece ser efectiva en cuanto fenómeno social y político para parte de los asentamientos fortificados tardíos del noroeste, si bien la propia biografía cultural de los mismos sobrepasaría este marco interpretativo hacia una realidad más compleja y dinámica.

\section{Balance y perspectiva de trabajo}

Partíamos en este trabajo del cuestionamiento de la categoría de castro en cuanto que su aplicación para el análisis de las fases tardías dentro de su secuencia de

\footnotetext{
105 Arias Vilas 1993; Rodríguez Fernández 1994.

106 Pérez Losada 1995.

107 Pérez Losada et alii 2008.

108 Carlsson-Brandt 2011a; 2011 b.

109 Arias Vilas 1996.

110 Castellanos - Martín Viso 2005.
} 
ocupación incorporaba distintas distorsiones y apriorismos que no sólo afectaban a su interpretación dentro de un contexto dado (el final del Imperio romano), sino que chocaban con la propia evidencia empírica. El avance en la investigación y las nuevas excavaciones y revisiones críticas están poniendo sobre la mesa estos problemas analíticos e interpretativos, aspecto que distintos autores han resaltado en mayor o menor medida. De esta manera, y en palabras de J. C. Sánchez Pardo, "Se hace necesaria una reflexión y contextualización de lo que significa un castro en cada período, tanto a nivel físico como histórico y social, algo que escasamente se suele encontrar". ${ }^{111}$ Este es el objetivo de la investigación en marcha y de la que aquí presentamos los primeros resultados y reflexiones. Una investigación que partía de esa necesidad de construir la casa por los cimientos y valorar críticamente la información efectivamente disponible sobre unos contextos de los que se ha escrito mucho, pero de los que se conocía realmente poco.

Esta revisión crítica ha permitido (re)elaborar un corpus de yacimientos que hemos categorizado como asentamientos fortificados de los siglos IV-VI, en aras de particularizar un fenómeno específico sin toda la carga y distorsión que suponen otros conceptos. Un corpus que muestra, en primera instancia, una debilidad empírica muy notable, con contextos con evidencias muy escasas, excavaciones poco sistemáticas e información inédita o muy dispersa. Sin duda, se hace necesario no sólo continuar con esta revisión crítica de los contextos y de los materiales concretos efectivamente disponibles, sino también realizar excavaciones más sistemáticas y con una clara orientación hacia la caracterización minuciosa de los contextos estratigráficos y las secuencias de ocupación. Si bien existen a día de hoy varios yacimientos para los que se dispone de una información suficiente, lo que muestran son secuencias de ocupación complejas, con potenciales soluciones de continuidad y momentos de abandono, así como fases de unas pocas generaciones. Secuencias que, al fin y al cabo, exigen un trabajo arqueológico minucioso para detectar con rigurosidad estas continuidades o discontinuidades que conforman la biografía cultural de cada yacimiento.

Por otro lado, la información recopilada permite sugerir algunas hipótesis de trabajo que guíen futuras investigaciones. Un aspecto relevante es que la evidencia disponible parece mostrar una variedad funcional y ocupacional de este tipo de asentamientos fortificados incluso contemporáneamente. Así, se han podido sugerir diferentes tipos de asentamientos en relación a su distribución espacial, su materialidad y las potenciales agencias detrás de la ocupación de los sitios durante las fases finales del Imperio romano y el inicio de la Alta Edad Media. Un panorama complejo y dinámico que habrá de profundizarse en el futuro con análisis microterritoriales que permitan depurar estas interpretaciones, así como incorporar nuevas cuestiones, como los análisis económicos a través de, por ejemplo, los registros bioarqueológicos, o los análisis sociales de estatus o género. De nuevo, para ello es necesaria una sólida base empírica y crítica que permita superar las distorsiones generadas por lecturas laxas de las secuencias de ocupación y de la materialidad asociada a los contextos.

Si bien se requieren análisis territoriales, el análisis en conjunto de los datos parece señalar algunas cuestiones significativas asociadas a estos asentamientos, sobre todo en relación a fenómenos similares en el resto de la Península Ibérica. Así, un aspecto común parece ser la base interpretativa en cuanto a que estos asentamientos

111 Sánchez Pardo 2010a, 130. 
representarían fundamentalmente las formas de adaptación, resistencia y resiliencia de las élites tardoimperiales a momentos de inestabilidad, no en términos étnicos o exclusivamente políticos, sino en cuanto cuestionamiento de las antiguas bases de poder y control. De esta manera, los asentamientos fortificados serían la consecuencia material de estas agencias, en aras de ejercer un control sobre el espacio y sobre las sociedades que lo habitaban. Es en este sentido en el que pensamos que el marco interpretativo de los castella tutiora es coherente con los datos, más aún dentro de las tempranas cronologías que muestran estos asentamientos. Por el contrario, la evidencia desborda estos marcos, insertándolos en contextos socio-políticos distintos a los que hace referencia el obispo de Chaves (que no deja de ser un agente interesado de estos cambios), como son la emergencia del nuevo poder suevo, la pugna por el control del comercio o el desarrollo de nuevos tipos de poblamiento rural en la forma de aldeas y granjas. Estas son sólo algunas hipótesis que esperamos poder ir clarificando en el futuro a medida que tanto la revisión crítica de la información disponible como las nuevas excavaciones vayan incorporando nuevos datos, leídos más allá de apriorismos o determinismos heredados.

\section{Referencias bibliográficas}

Almeida, C. A. F. (1993): “Arqueoloxía tardorromana e germánica no NW peninsular”, [en] VV. AA. (eds.), 1993, 191-200.

Álvarez González, Y. - López González, L. F. - Fernández Götz, M. A. - García Quintela, M. V. (2017): "El oppidum de San Cibrán de Las y el papel de la religión en los procesos de centralización den la Edad del Hierro", CuPAUAM 43, 217-239 (https://doi.org/10.15366/ cupauam2017.43.008).

Amorós Ruiz, V. - Doménech Belda, C. (2020): "Espacio, tiempo y monedas en el Tolmo de Minateda", [en] S. Gutiérrez Lloret (ed.), El sitio de las cosas. La Alta Edad Media en contexto, Alicante, 161-174.

Arias Vilas, F.

(1984): "La cultura castrexa en Galicia", Memorias de Historia Antigua 6, 15-34.

(1993): “Apuntes sobre a ocupación do territorio na Galicia baixorromana: castros e vilas", [en] VV. AA. (eds.), 1993, 201-208.

(1996): "Poblamiento rural: la fase tardía de la cultura castreña", [en] C. Fernández Ochoa (ed.), Los finisterres atlánticos en la Antigüedad: época prerromana y romana (=Patrimonio 2), Gijón, 181-188.

Arias Vilas, F. - Durán Fuentes, M. C. (1996): Museo do Castro de Viladonga (Castro de Rei, Lugo), Santiago de Compostela.

Ariño Gil, E. - Díaz Martínez, P. D. L. C. (2014): “La frontera suevo-visigoda: ensayo de la lectura de un territorio en disputa", [en] Catalán Ramos - Fuentes Melgar - Sastre Blanco (eds.), 2014, 179-190.

Arizaga Castro, Á. - Ayán Vila, X. (2007): “Etnoarqueología del paisaje castreño. La segunda vida de los castros", [en] F. J. González García (ed.), Los pueblos de la Galicia Céltica, Madrid, 445-531.

Balboa De Paz, J. A. - Díaz Álvarez, I. - Fernández Vázquez, V. (eds.), (2003): Actas de las Jornadas sobre Castro Ventosa, Cacabelos.

Bello Diéguez, J. M. (2018): "Bajo Imperio y Tardorromanidad en el Castro de Elviña (A Coruña)", Boletín del Museo Arqueológico Nacional 37, 131-148. 
Bouza Brey, F. (1948): "Moneda visigoda hallada en San Cibrán de Lás”, Cuadernos de Estudios Gallegos 3, 155.

Brogiolo, G. P. (2000): “Towns, Forts and the Countryside: Archaeological Models for Northern Italy in the Early Lombard Period (AD 568-650)", [en] G. P. Brogiolo - N. Gauthier - N. Christie (eds.), Towns and Their Territories between Late Antiquity and the Early Middle Ages (=Transformation of the Roman World 9), Leiden, 299-323 (https:// doi.org/10.1163/9789004474796_016).

Caballero Arribas, J. - Peñas Pedrero, D. (2012): "Un castrum de época visigoda en el valle Amblés: La Cabeza de Navasangil (Solosancho, Ávila)", [en] Quirós Castillo - Tejado Sebastián (eds.), 2012, 213-238.

Candelas Colodrón, C.

(2001): “«Plebs»y aristocracia en el Cronicón de Hidacio: la organización política hispanorromana en el siglo V", Polis. Revista de ideas y formas politicas de la Antigüedad Clásica 13, 129-139.

(2004): O Cronicón de Hidacio. Bispo de Chaves, A Coruña.

Carlsson-Brandt Fontán, E.

(2011a): "El poblamiento rural en la Galicia Romana. Un ejemplo: las villae. Metodología y problemática en su estudio", Estrat Crític 5/1, 156-167.

(2011b): "El Poblamiento rural romano en Galicia. Resultados preliminares", Férvedes 7 , 207-213.

Caselles López, I. (2016): Niveles de ocupación tardoantigua de castros de Galicia. Una revisión arqueológica, Trabajo Fin de Máster, Universidade de Santiago de Compostela.

Castellanos, S. - Martín Viso, I. (2005): "The Local Articulation of Central Power in the North of the Iberian Peninsula (500-1000)", Early Medieval Europe 13/1, 1-42 (http:// dx.doi.org/10.1111/j.1468-0254.2005.00147.x).

Catalán Ramos, R. - Fuentes Melgar, P. - Sastre Blanco, J. C. (eds.), (2014): Las fortificaciones en la tardoantigüedad. Élites y articulación del territorio (siglos V-VIII d. C.), Madrid.

Cepeda, J. J.

(1988): “Tesorillos monetarios en el norte y noroeste de la Península Ibérica entre la segunda mitad del siglo IV y la primera mitad del siglo V d.C.", [en] 25 años. Facultad de Filosofía y Letras II. Estudios de Geografia e Historia, Bilbao.

(1993): "Monedas procedentes del castro de Penadominga (Bendollo, Quiroga. Lugo)", Numisma 232, 91-107.

Chamoso Lamas, M. (1975): “Avance informativo sobre las excavaciones arqueológicas realizadas en Bretoña (Lugo) durante las campañas de 1970 y 1971”, Noticiario Arqueológico Hispánico 4, 266-271.

Díaz Álvarez, I. - Garín, A. (1999): "Estudio de los materiales arqueológicos de Castro Ventosa", Estudios Bercianos 25, 74-95.

Díaz Martínez, P. C. (2011): El Reino Suevo (411-585), Madrid.

Dinis, M. V. (1976): “O castro de S. Brás, Frazão, Paços de Ferreira”, Revista de Guimarães $86,217-222$.

Domínguez Bolaños, A. - Nuño González, J. (2014): “Dos viviendas del siglo VI sin noticias de élites locales en el Cristo de San Esteban (Muelas del Pan, Zamora)", [en] Catalán Ramos - Fuentes Melgar - Sastre Blanco (eds.), 2014, 275-296.

Dorribo Cao, J. R. (1995): "O castro de Formigueiros: unha aproximación ó seu estudo arqueolóxico", Historia Nova 2, 9-24.

Durán Fuentes, M. C. (2009): Moedas do Museo do Castro de Viladonga, Santiago de Compostela. 
Espada Ballesteros, A. A. (2013): "Historia de la investigación en el castro de Fazouro, Foz (Lugo). Reflexiones para su puesta en valor", CROA. Boletín da Asociación de Amigos do Museo do Castro de Viladonga 23, 22-29.

Fernández Fernández, A. (2014): El comercio tardoantiguo (ss. IV-VII) en el Noroeste peninsular a través del registro cerámico de la ría de Vigo (=Roman and Late Antique Mediterranean Pottery 5), Oxford (http://dx.doi.org/10.2307/j.ctvz937ss).

Fernández Fernández, A. - Bartolomé Abraira, R. (2016): “Cerámicas tardoantiguas en el noroeste de la Península (Galicia y norte de Portugal): entra la importación y el artesanado local/regional", [en] J. A. Quirós Castillo - A. Vigil-Escalera (eds.), La cerámica de la Alta Edad Media en el cuadrante noroeste de la Península Ibérica (siglos V-X): sistemas de producción, mecanismos de distribución y patrones de consumo (=Universidad del País Vasco. Documentos de Arqueología Medieval 9), Bilbao, 69-111.

Fernández Fernández, A. - Carvalho, P. C. - André, C. - Costa, M. - Tereso, S. (2018): "Contextos cerámicos de época alto y bajo imperial provenientes de La Torre VelhaCastro de Avelas (Bragança, Portugal)", [en] Rei Cretariae Romanae Fautorum. Acta 45, Bonn, 71-81.

Fernández Fernández, A. - Rodríguez Novoa, A. A. (2016): “Contextos cerámicos de época romana de la "cibdá” de Armea (Santa Mariña de Augas Santas, Allariz). Un ejemplo de consumo y abastecimiento de una ciudad galaico-romana del interior de la Gallaecia", [en] R. Járrega - P. Berni (eds.), Amphorae ex Hispania: paisajes de producción y consumo (=ICAC. Monografías Ex Officina Hispana III), Tarragona, 861-873.

Fernández Pereiro, M.

(2017): "Mais lá da Cultura Castreja: castros ex-novo durante a antiguidade tardía no noroeste da Gallaecia”, [en] A. Vázquez Martínez - R. Cordeiro Macenlle - M. Carrero Pazos - M. Díaz Rodríguez - A. A. Rodríguez Nóvoa - B. Vilas Estévez (eds.), (Re)escribindo a Historia. Achegas dos novos investigadores en Arqueoloxía e Ciencias da Antigüidade, Santiago de Compostela, 287-298.

(2018): Recintos fortificados en altura na costa atlántica galega. Estudo arqueolóxico, Tesis doctoral, Universidade de Santiago de Compostela.

Fernández Pereiro, M. - Sánchez Pardo, J. C. - Alonso Toucido, F. (2020): “Fortificaciones y control del territorio en la Gallaecia Altomedieval. Estudio arqueológico del yacimiento de Faro de Budiño (O Porriño, Pontevedra)", Munibe. Antropologia-Arkeologia 71, 163 180 (http://dx.doi.org/10.21630/maa.2020.71.04).

Fernández Pereiro, M. - Tejerizo García, C. - Rodríguez González, C. - Lixó Gómez, C. Carvajal Castro, Á. (2017): “Asentamentos fortificados no interior da Gallaecia en época tardoimperial e sueva (séc. IV-VI): un achegamento a partir de varios casos de estudo", Gallaecia 36, 129-162 (http://dx.doi.org/10.15304/gall.36.5104).

Fernández Rodríguez, C. (2020): Análisis de los restos óseos de macromamíferos del yacimiento de O Castelo de Valencia do Sil (Vilamartín de Valdeorras, Ourense). Intervención 2019, Informe depositado en la Dirección Xeral de Patrimonio, Santiago de Compostela.

Fontes, L. O. (2017): “O sítio arqueológico da Falperra (Braga)”, [en] López Quiroga (ed.), 2017, 201-204.

González Ruibal, A.

(2005): "El castro de Saceda y la jerarquización territorial de la Segunda Edad del Hierro en el noroeste ibérico", Zephyrus 58, 267-284.

(2006-2007): Galaicos. Poder y comunidad en el Noroeste de la Península Ibérica (1200 a.C-50 d.C.), (=Brigantium 18-19), A Coruña. 
Halsall, G. (2014): “Two Worlds Become One: A 'Counter-Intuitive' View of the Roman Empire and 'Germanic' Migration”, German History 32/4, 515-532 (http://dx.doi. org/10.1093/gerhis/ghu107).

Kopytoff, I. (1986): "The cultural biography of things: commoditization as process", [en] A. Appadurai (ed.), The Social Life of Things: Commoditization in Cultural Perspective, Cambridge, 64-92 (https://doi.org/10.1017/CBO9780511819582.004).

Lage Pillado, M. (2004): Fíbulas galaico-romanas do Castro de Viladonga (=Estudos de Museos 1), Santiago de Compostela.

Llana Rodríguez, J. C. - Varela Arias, E. (2001): "Las primeras excavaciones en el castro de Viladonga, treinta años después", CROA. Boletín da Asociación de Amigos do Museo do Castro de Viladonga 11, 11-24.

López Quiroga, J.

(2004): El final de la Antigüedad en la Gallaecia: la transformación de las estructuras de poblamiento entre Miño y Duero (siglos V al X), La Coruña.

(2017): "Hábitat, poblamiento y territorio en la Gallaecia de la época sueva", [en] López Quiroga (ed.), 2017, 163-171.

López Quiroga, J. (ed.), (2017): In tempore Sueborum. El tiempo de los suevos en la Gallaecia (411-585). El primer reino medieval de Occidente, Ourense.

López Quiroga, J. - Rodríguez Lovelle, M. (1999): “Castros y castella tutiora de época sueva en Galicia y norte de Portugal: ensayo de inventario y primeras propuestas interpretativas", Hispania Antiqua 23, 355-374.

Marín Suárez, C. (2005): Astures y asturianos. Historiografía de la Edad de Hierro en Asturias (=Keltia 27), Madrid.

Martínez Jiménez, J. - Tejerizo García, C. (2015): “Central Places in the Post-Roman Mediterranean: Regional Models for the Iberian Peninsula", Journal of Mediterranean Archaeology 28/1, 81-103 (http://dx.doi.org/10.1558/jmea.v28i1.27502).

Nieto Muñíz, E.-B. (2019): Memoria de escavación-San Tomé 2019. Escavación arqueolóxica, consolidación e musealización no conxunto arqueolóxico-natural de Santomé (Ourense), Memoria inédita depositada en la Dirección Xeral de Patrimonio, Santiago de Compostela.

Palol, P. D. (1969): "La necrópolis de San Miguel del Arroyo y los broches hispanorromanos del siglo IV", Boletín del Seminario de Estudios de Arte y Arqueología 34-35, 93-160.

Pérez Losada, F.

(1995): "Arqueoloxía e arte no mundo rural: hábitat e arquitectura das villae galaicorromanas", [en] F. Pérez Losada - L. Castro Pérez (eds.), Arqueoloxía e arte na Galicia prehistórica e romana, A Coruña, 165-188.

(2002): Entre a cidade e a aldea. Estudio arqueo-histórico dos "aglomerados secundarios" romanos en Galicia, A Coruña.

Pérez Losada, F. - Fernández Fernández, A. - Vieito Covela, S. (2008): “Toralla y las villas marítimas de la Gallaecia atlántica. Emplazamiento, arquitectura y función”, [en] C. Fernández Ochoa - V. García Entero - F. Gil Sendino (eds.), Las “villae” tardorromanas en el Occidente del Imperio: arquitectura y función, Gijón, 481-506.

Pérez Rozas, Á. (2017): “A produción téxtil na cultura castrexa: as fusaiolas do Castro de Viladonga (Castro de Rei, Lugo)", CROA. Boletín da Asociación de Amigos do Museo do Castro de Viladonga 27, 32-51.

Quirós Castillo, J. A. (2012): «Introducción”, [en] Quirós Castillo - Tejado Sebastián (eds.), 2012, 17-27.

Quirós Castillo, J. A. (ed.), (2018): Treinta años de Arqueología Medieval en España, Oxford. 
Quirós Castillo, J. A. - Tejado Sebastián, J. M. (eds.), (2012): Los castillos altomedievales en el noroeste de la Península Ibérica (=Universidad del País Vasco. Documentos de Arqueología Medieval 4), Bilbao.

Rey Castiñeira, J. - Abad Vidal, E. - Calo Ramos, N. - Candamo Bueno, C. - Comesaña Cortegoso, M. - Martín Seijo, M. (2010): Formigueiros. Análise da cultura material, Santiago de Compostela.

Rodríguez Fernández, T. (1994): “El fin del mundo fortificado y la aparición de las 'aldeas abiertas'. La evidencia del centro-oriente de Lugo (Samos y Sarria)", Espacio, Tiempo y Forma. Serie I, Prehistoria y Arqueología 7, 153-189.

Rodríguez González, X. (1984): La villa romana de San Tomé (Ourense), Ourense.

Rodríguez González, X. - Xusto Rodríguez, M. (2019): Santomé. Conxunto arqueolóxico natural, Ourense.

Rodríguez Resino, Á. (2006): Del Imperio Romano a la Alta Edad Media. Arqueología de la Tardoantigüedad en Galicia (siglos V-VIII), Noia.

Rodríguez Sánchez, B. (2012): “O proceso de abandono dos castros. 'Continuidades' e 'rupturas' entre a Idade do Ferro e a Alta Idade Media. Un estado da cuestión”, Gallaecia 31, 139-151.

Russell Cortez, F. (1951): “As escavações arqueologicas do castellum da Fonte do Milho: contributo para a demogenia Duriense", Anais do Instituto do Vinho do Porto 12, 17-88.

Sánchez Pardo, J. C.

(2010a): “Castros y aldeas galaicorromanas: sobre la evolución y transformación del poblamiento indígena en la Galicia romana”, Zephyrus 65, 129-148.

(2010b): "Poblamiento rural tardorromano y altomedieval en Galicia (ss. V-X). Una revisión arqueológica", Archeologia Medievale 37, 285-306.

(2012): "Castros, castillos y otras fortificaciones en el paisaje sociopolítico de Galicia (siglos IV-XI)", [en] Quirós Castillo - Tejado Sebastián (eds.), 2012, 29-56.

(2013): "Power and Rural Landscapes in Early Medieval Galicia (400-900 AD): Towards a Re-Incorporation of the Archaeology into the Historical Narrative", Early Medieval Europe 21/2, 140-168 (https://doi.org/10.1111/emed.12013).

(2015): "Power Strategies in the Early Medieval Churches of Galicia (711-910 AD)", [en] J. C. Sánchez Pardo - M. G. Shapland (eds.), Churches and Social Power in Early Medieval Europe. Integrating Archaeological and Historical Approaches (=Studies in the Early Middle Ages 42), Turnhout, 227-268 (https://doi.org/10.1484/M.SEMEB.5.108510).

Sánchez Pardo, J. C. - Galbán Malagón, C. J. (2014): "Fortificaciones de altura en el entorno de Santiago de Compostela. Hacia un primer análisis arqueológico comparativo", Nailos 2, 125-161.

Sastre Blanco, J. C. - Fuentes Melgar, P. - Rodríguez Monterrubio, Ó. (2014): “El poblado fortificado de El Castillón en el contexto del siglo V d.C.”, [en] Catalán Ramos - Fuentes Melgar - Sastre Blanco (eds.), 2014, 353-368.

Tejerizo García, C.

(2017): Arqueología de las sociedades campesinas en la cuenca del Duero durante la Primera Alta Edad Media (=Universidad del País Vasco. Documentos de Arqueología Medieval 11), Bilbao.

(2020): "El poblamiento en el interior de la Gallaecia entre el final del Imperio Romano y la Alta Edad Media: nuevos datos, nuevas propuestas", Studia Historica. Historia Medieval 38/2, 155-187 (https://doi.org/10.14201/shhme2020382155187). 
Tejerizo García, C. - Canosa Betés, J. (2018): "Power, control and social agency in postroman northern Iberia: an archaeological analysis of hillfort occupations", Journal of Medieval Iberian Studies 10/3, 295-323 (https://doi.org/10.1080/17546559.2018.1504 383).

Tejerizo García, C. - Rodríguez González, C. (2019): Proxecto de escavación do asentamento fortificado de Valencia do Sil (Vilamartín de Valdeorras, Ourense), Memoria inédita depositada en la Dirección Xeral de Patrimonio Cultural, Santiago de Compostela.

Tejerizo García, C. - Rodríguez González, C. - Fernández Pereiro, M.

(2018): "Materiais cerámicos tardíos (ss. IV-VI d.C.) no castro de Viladonga", CROA. Boletín da Asociación de Amigos do Museo do Castro de Viladonga 28, 36-52.

(2019): “¿Continuidad o discontinuidad en los castros del noroeste? Una revisión del yacimiento de Viladonga (Castro de Rei, Lugo)", SPAL 28/2, 279-313 (http://dx.doi. $\operatorname{org} / 10.12795 /$ spal.2019.i28.22).

Tejerizo García, C. - Scaro, A. - Daflon, E. C. (2019): "Materiales inéditos del asentamiento fortificado de Valencia do Sil (Vilamartín de Valdeorras, Ourense)", Gallaecia 38, 71-101 (http://dx.doi.org/10.15304/gall.38.5949).

Tejerizo García, C. - Vigil-Escalera, A. (2017): “Castro Ventosa y La Cabeza de Navasangil: una revisión de sus secuencias de ocupación y del fenómeno de los asentamientos fortificados altomedievales", Nailos 4, 129-161.

Tranoy, A. (1981): La Galice Romaine. Recherches sur le nord-ouest de la péninsule Ibérique dans l'Antiquité, Paris.

Varela Barrios, C. - Cavada Nieto, M. M. - Rodríguez González, X. (1997): “La circulación monetaria en el conjunto arqueológico de Santomé (Ourense), siglos I al V d. C.", Boletín Auriense 27, 51-106.

Vigil-Escalera, A.

(2007): "Granjas y aldeas altomedievales al norte de Toledo (450-800 d. C.)", Archivo Español de Arqueología 80, 239-284.

(2012): "El asentamiento encastillado altomedieval de la Dehesa de la Oliva (Patones, Madrid)", [en] Quirós Castillo - Tejado Sebastián (eds.), 2012, 239-262.

Vigil-Escalera, A. - Tejerizo García, C. (2014): “Asentamientos fortificados altomedievales en la Meseta: algunas distorsiones historiográficas", [en] Catalán Ramos - Fuentes Melgar - Sastre Blanco (eds.), 2014, 229-245.

VV. AA. (eds.), (1993): Galicia: da romanidade á xermanización. Problemas históricos e culturais. Actas do encontro cientifico en homenaxe a Fermín Bouza Brey (1901-1973), Santiago de Compostela. 
Tabla 1. Asentamientos fortificados considerados en el trabajo

\begin{tabular}{|c|c|c|c|c|c|c|}
\hline ID & Nombre & Lugar & $\begin{array}{c}\text { Extensión } \\
\text { (ha) }\end{array}$ & Excavado & $\begin{array}{c}\text { Fase } \\
\text { Previa } \\
\end{array}$ & Dudoso \\
\hline 1 & Santa María de Mones & A Rúa & 1,54 & No & Sí (dudosa) & \\
\hline 2 & O Castelo & Vilamartín de Valdeorras & 4 & Sí & Sí & \\
\hline 3 & Penadominga & Bendollo & 0,7 & No & No & \\
\hline 4 & Castro da Pereira & Baleira & 3,1 & No & - & Sí \\
\hline 5 & $\begin{array}{c}\text { Bretoña, Santa María de } \\
\text { Britonia }\end{array}$ & A Pastoriza & - & Sí & Sí & Sí \\
\hline 6 & Castro de Piñeira & Ribadeo & 0,68 & No & Sí & Sí \\
\hline 7 & Santa Mariña & Navia de Suarna & 0,4 & No & No & \\
\hline 8 & Alobre & Vilagarcía de Arousa & 1,82 & Sí & Sí & \\
\hline 9 & Castrogudín & Vilagarcía de Arousa & 1,98 & No & - & Sí \\
\hline 10 & Calvario & Santa Marina de Rosal & 1 & No & - & \\
\hline 11 & Altamira & Taboexa & 5,06 & Sí & Sí & \\
\hline 12 & Peneda do Viso & Redondela & 2,28 & No & Sí & \\
\hline 13 & Castro Ventosa & Cacabelos & 3 & Sí & Sí & \\
\hline 14 & La Muela & Villablino & 2,1 & Sí & Sí & \\
\hline 15 & Santa Tegra & A Guarda & 20 & Sí & Sí & Sí \\
\hline 16 & Outeiro do Castro & Ponte Hermida & - & No & - & Sí \\
\hline 17 & Novás & Xinzo de Limia & 1,16 & Sí & - & \\
\hline 18 & Cida de San Millán & Cualedro & 2,68 & Sí & Sí & Sí \\
\hline 19 & Santomé & Ourense & 2,38 & Sí & Sí & \\
\hline 20 & Budiño & O Porriño & 6 & Sí & No & \\
\hline 21 & Castro de Devesa & Folgoso do Courel & 0,5 & No & - & Sí \\
\hline 22 & Cruz do castro & Cotobade & 0,88 & Sí & Sí & Sí \\
\hline 23 & Tui & Tui & & & & \\
\hline 24 & Elviña & A Coruña & 2,45 & Sí & Sí & \\
\hline 25 & El Caleyu & La Cuesta & 0,6 & Sí & No & \\
\hline 26 & Torre Velha & Castro de Avelãs & 3 & Sí & Sí & \\
\hline 27 & Crestuma & Vila Nova de Gaia & 1,7 & Sí & Sí & \\
\hline 28 & Monte Castrelo de Pelóu & Grandas de Salime & 3 & Sí & Sí & Sí \\
\hline 29 & Curralha & Chaves & - & Sí & - & \\
\hline 30 & Saceda & Cualedro & 5 & Sí & Sí & Sí \\
\hline 31 & Fiães & Santa Maria da Feira & 3 & Sí & Sí & \\
\hline 32 & Guifões & Matosinhos & 2,9 & Sí & Sí & \\
\hline 33 & São Bras & Paços de Ferreira & 1,2 & & Sí & \\
\hline 34 & Eiros & Arcos de Valdevez & - & - & - & Sí \\
\hline 35 & Monte do Castro & Viana do Castelo? & - & No & - & Sí \\
\hline 36 & $\begin{array}{c}\text { Castro de Barbudo/Monte } \\
\text { do Castelo }\end{array}$ & Vila Verde & - & - & - & Sí \\
\hline
\end{tabular}




\begin{tabular}{|c|c|c|c|c|c|c|}
\hline ID & Nombre & Lugar & $\begin{array}{c}\text { Extensión } \\
\text { (ha) }\end{array}$ & Excavado & $\begin{array}{c}\text { Fase } \\
\text { Previa }\end{array}$ & Dudoso \\
\hline 37 & Portomeiro & Val do Dubra & 0,5 & Sí & - & Sí \\
\hline 38 & Viladonga & Castro de Rei & 4 & Sí & Sí & \\
\hline 39 & Falperra & Braga & 3,5 & Sí & - & \\
\hline 40 & Astorga & & 31 & Sí & Sí & \\
\hline 41 & Braga & & 70 & Sí & Sí & \\
\hline 42 & Lugo & & 34 & Sí & Sí & \\
\hline 43 & Vigo & & 3,3 & Sí & Sí & \\
\hline
\end{tabular}

